\title{
Campos Organizacionais: Seis Diferentes Leituras e a Perspectiva de Estruturação( ${ }^{(1)}$
}

\section{Organizational Fields and the Structuration Perspective: Analytical Possibilities}

Clóvis L. Machado-da-Silva ${ }^{(2)}$

Ph.D. em Estudos Organizacionais e Estratégia pela Michigan State University, EUA. Professor Titular do CEPPAD/UFPR e Professor do PMDA/UP, Curitiba/PR, Brasil.

Edson R. Guarido Filho * Doutor em Administração de Empresas pelo CEPPAD/UFPR. Professor do PMDA/UP, Curitiba/PR, Brasil.

Luciano Rossoni Doutor em Administração de Empresas pelo CEPPAD/UFPR. Professor do PMDA/UP, Curitiba/PR, Brasil.

* Endereço: Edson R. Guarido Filho

Programa de Mestrado e Doutorado em Administração (PMDA), Universidade Positivo (UP), Rua Prof. Pedro Viriato Parigot de Souza, 5300, Prédio da Biblioteca, $5^{\circ}$ andar, Curitiba/PR, 81280-330. E-mail: edson.guarido@gmail.com

Este artigo foi originalmente publicado na Revista de Administração Contemporânea RAC, v. 10, Edição Especial, Maio, 2006, disponível no endereço www.anpad.org.br/rac. 


\title{
RESUMO
}

O conceito de campo organizacional vem sendo tratado com certo destaque na literatura sobre teoria institucional, nos últimos anos. Como o conceito de campo envolve uma dimensão relacional e outra simbólica, propomos que a teoria da estruturação, baseada na lógica de recursividade entre agência e estrutura, seja adequada para o entendimento do campo de maneira dinâmica. Nesse sentido, o objetivo do presente ensaio teórico é tratar a dinâmica do campo organizacional sob uma lógica estruturacionista, admitindose que a partir dela se resgata tanto a importância da prática no processo de estruturação do campo organizacional como o caráter histórico e recursivo, que tanto constrange como habilita as ações dos atores sociais. Para tanto, revisamos o conceito de campo em diferentes perspectivas de análise, refletindo sobre as implicações dos pressupostos teóricos de cada abordagem e, em seguida, discutimos criticamente a fundamentação teórica do processo de estruturação de campos organizacionais com base na abordagem estruturacionista. Concluímos o ensaio com proposições acerca da revisão do conceito de campo sob uma ótica multiparadigmática, na qual estrutura e agência estão recursivamente implicadas.

Palavras-chave: teoria institucional; teoria da estruturação; campos organizacionais; estrutura social; atores sociais e agência.

\begin{abstract}
The concept of the organizational field has been greatly dealt with in the literature on institutional theory in recent years. As the concept of field involves a relational and symbolic dimension, we propose that the theory of structuration, based on the logic of recursiveness between agency and structure should be adapted to the understanding of the field dynamically. In this way, the objective of this theoretical essay is to deal with the dynamic of the organizational field using structurationist logic, allowing that from this logic we recall both the importance of the practice in the structuration process of the organizational field and the historical and recursive character which may constrain or enable the actions of social actors. To this end, we revise the concept of field in different perspectives of analysis, reflecting on the implication of the theoretical presuppositions of each approach and then discuss in a critical manner the theoretical foundation of the structuration process of organizational fields based on the structurationist approach. We conclude the paper with propositions pertaining to the revision of the concept of field from a multiparadigmatic viewpoint in which structure and agency are recursively implied.
\end{abstract}

Key words: institutional theory; structuration theory; organizational fields; social structure; social actors and agency. 


\section{INTRODUÇÃO}

As relações entre organizações e outros atores sociais não representam apenas uma estrutura resultante de suas atividades, mas também definem e delimitam suas possibilidades para a ação, numa perspectiva mais interativa e recíproca do processo de institucionalização. Nessa linha de raciocínio, o tratamento do conceito de campo organizacional, com base na noção de estruturação, permite que se incorpore uma lógica de recursividade na análise da relação entre agência e estrutura em um contexto espaciotemporalmente delimitado. Além disso, possibilita que se leve em conta não apenas a dimensão relacional, mas também a dimensão simbólica no campo organizacional.

Nesse sentido, o presente trabalho caracteriza-se como um ensaio teórico, cujo objetivo é tratar a dinâmica do campo organizacional sob uma lógica estruturacionista. Admitimos que a partir desta lógica se resgata a importância da prática no processo de estruturação do campo organizacional e o seu caráter histórico e recorrente, que tanto constrange como habilita as ações dos atores sociais.

Como se poderá observar no desdobramento do artigo, a abordagem que adotamos pressupõe um modelo de atividade social recursivo e não-teleológico com o objetivo de reposicionar a noção de campo nos estudos organizacionais e evitar que se recaia em imprudências epistemológicas e teóricas favorecedoras: (i) da ontologização do campo, enquanto realidade de fato e completa (realismo radical); (ii) da reificação, atribuindo ao campo uma existência independente; (iii) do voluntarismo, supondo que o campo é produto exclusivo da ação humana; (iv) do funcionalismo, entendendo que o campo e suas relações resultam de necessidades funcionais dos atores sociais; (v) do normativismo, vislumbrando o campo meramente como uma representação social da realidade que impõe parâmetros para ação, caracterizando a supersocialização do ator.

O recorte analítico deste artigo apóia-se na preocupação apresentada por autores como DiMaggio e Powell (1991): apesar do novo institucionalismo, em comparação com os primeiros estudos da teoria institucional, ter elevado o nível da autoridade formal e da capacidade de organização do âmbito das elites locais para níveis mais amplos, essa face macrosociológica parece repousar sobre uma microsociologia pouco explicitada. Tal microsociologia funda-se em uma teoria cognitiva, que enfatiza as tipificações rotineiras e os 
comportamentos culturalmente sustentados e conceitualmente corretos do ponto de vista social, bem como na noção de agência no processo de institucionalização. Essa relação indica a necessidade de se trabalhar com múltiplos níveis na análise institucional, já que sistemas simbólicos, como regras e conceitos, são, em princípio, "idéias ou valores nas cabeças dos atores organizacionais" (Scott, 2001, p. 79).

Para tanto, o artigo está organizado em duas grandes seções: na primeira delas, apresentamos o conceito de campo organizacional com base em diferentes perspectivas de análise, refletindo sobre as implicações de determinados pressupostos teóricos para a explicação institucional adotada; e, na segunda, discutimos criticamente a fundamentação teórica do processo de estruturação de campos organizacionais com base na abordagem estruturacionista. Concluímos o trabalho com proposições acerca da revisão do conceito de campo sob uma ótica multiparadigmática e integracionista, na qual estrutura e agência estão recursivamente implicadas.

\section{Perspectivas Teóricas sobre Campos Organizacionals}

O conceito de campo organizacional emerge como "unidade fundamental na associação dos níveis organizacional e societário no estudo da mudança social e da comunidade" (DiMaggio, 1986, p. 337), possibilitando trabalhar a complexa inter-relação entre os ambientes de recursos materiais, competitivo e institucional, de modo mais adequado do que modelos populacionais precedentes (DiMaggio \& Powell, 1982; Scott, 1991, 2004). No entanto, desde a sua definição inicial até os dias atuais um amplo debate se formou em torno do assunto e diferentes acepções têm sido apresentadas na tentativa de aperfeiçoar o próprio conceito e a sua operacionalização.

O reconhecimento da multiplicidade de abordagens sobre o tema, em alguns casos com diferenciações sutis, levou-nos à classificação de seis perspectivas teóricas sobre campos organizacionais, conforme se pode verificar na Tabela 1. 
Tabela 1

\section{Perspectivas Teóricas sobre Campos Organizacionais}

\begin{tabular}{|c|c|c|c|}
\hline $\begin{array}{l}\text { Perspectiva } \\
\text { Teórica }\end{array}$ & Autores & Elementos-Chaves & Descrição \\
\hline $\begin{array}{l}\text { Campo como a } \\
\text { totalidade dos } \\
\text { atores relevantes }\end{array}$ & $\begin{array}{l}\text { DiMaggio; } \\
\text { Powell. }\end{array}$ & $\begin{array}{l}\text { Significação e } \\
\text { Relacionamento }\end{array}$ & $\begin{array}{l}\text { Conjunto de organizações que compartilham sistemas de } \\
\text { significados comuns e que interagem mais } \\
\text { freqüentemente entre si do que com atores de fora do } \\
\text { campo, constituindo assim uma área reconhecida da vida } \\
\text { institucional. }\end{array}$ \\
\hline $\begin{array}{l}\text { Campo como } \\
\text { arena } \\
\text { funcionalmente } \\
\text { específica }\end{array}$ & $\begin{array}{l}\text { Scott; } \\
\text { Meyer. }\end{array}$ & Função Social & $\begin{array}{l}\text { Conjunto de organizações similares e diferentes, porém } \\
\text { interdependentes, operando numa arena funcionalmente } \\
\text { específica, compreendida técnica e institucionalmente, em } \\
\text { associação com seus parceiros de troca, fontes de } \\
\text { financiamento e reguladores. }\end{array}$ \\
\hline $\begin{array}{l}\text { Campo como } \\
\text { centro de diálogo } \\
\text { e de discussão }\end{array}$ & $\begin{array}{l}\text { Hoffman; } \\
\text { Zietsma; } \\
\text { Winn. }\end{array}$ & $\begin{array}{l}\text { Debate por } \\
\text { Interesse Temático }\end{array}$ & $\begin{array}{l}\text { Conjunto de organizações, muitas vezes com propósitos } \\
\text { díspares, que se reconhecem como participantes de um } \\
\text { mesmo debate acerca de temáticas específicas, além } \\
\text { daquelas preocupadas com a reprodução de práticas ou de } \\
\text { arranjos institucionais relacionados à questão. }\end{array}$ \\
\hline $\begin{array}{l}\text { Campo como } \\
\text { arena de poder e } \\
\text { de conflito }\end{array}$ & $\begin{array}{l}\text { Vieira; } \\
\text { Carvalho; } \\
\text { Misoczky. }\end{array}$ & $\begin{array}{l}\text { Dominação e } \\
\text { Poder de Posição }\end{array}$ & $\begin{array}{l}\text { Campo como resultado da disputa por sua dominação, } \\
\text { numa dinâmica pautada pela (re)alocação de recursos de } \\
\text { poder dos atores e pela sua posição relativa a outros } \\
\text { atores. }\end{array}$ \\
\hline $\begin{array}{l}\text { Campo como } \\
\text { esfera } \\
\text { institucional de } \\
\text { interesses em } \\
\text { disputa }\end{array}$ & $\begin{array}{l}\text { Fligstein; } \\
\text { Swedberg; } \\
\text { Jepperson. }\end{array}$ & $\begin{array}{l}\text { Poder e Estruturas } \\
\text { Cognitivas }\end{array}$ & $\begin{array}{l}\text { Construções produzidas por organizações detentoras de } \\
\text { poder, que influenciam as regras de interação e de } \\
\text { dependência do campo em função de seus interesses, que, } \\
\text { por sua vez, são reflexos da posição delas na estrutura } \\
\text { social. }\end{array}$ \\
\hline $\begin{array}{l}\text { Campo como } \\
\text { rede estruturada } \\
\text { de } \\
\text { relacionamentos }\end{array}$ & $\begin{array}{l}\text { Powell; } \\
\text { White; } \\
\text { Owen-Smith }\end{array}$ & $\begin{array}{l}\text { Articulação } \\
\text { Estrutural }\end{array}$ & $\begin{array}{l}\text { Conjunto formado por redes de relacionamentos } \\
\text { usualmente integradas e entrelaçadas, que emergem como } \\
\text { ambientes estruturados e estruturantes para organizações } \\
\text { e indivíduos, revelados a partir de estudos topológicos e } \\
\text { de coesão estrutural. }\end{array}$ \\
\hline
\end{tabular}

Nota. Fonte: Literatura especializada sobre campos organizacionais.

\section{Campo como a Totalidade dos Atores Relevantes}

DiMaggio e Powell (1983) definem campo organizacional como "aquelas organizações que, em conjunto, constituem uma área reconhecida da vida institucional: fornecedores-chaves, consumidores de recursos e produtos, agências reguladoras e outras organizações que produzem serviços ou produtos similares" (p. 148). Nesta ótica, enquanto área reconhecida da vida institucional, campos organizacionais representam a totalidade dos atores relevantes, ou seja, "uma comunidade de organizações que compartilham sistemas de significados comuns e cujos participantes interagem mais freqüentemente e decisivamente entre eles do que com atores de fora do campo" (Scott, 1994, pp. 207-208). Como destacam DiMaggio e Powell (1983), um campo estruturado corresponde a um complexo de organizações respondendo a um ambiente de respostas organizacionais, no 
sentido delas representarem estruturalmente suas relações ao mesmo tempo em que delimitam as ações formuladas em seus relacionamentos.

Compreendido dessa maneira, está inerente ao conceito tanto um componente relacional entre os atores sociais como a presença de estruturas institucionais comuns, que são construídas segundo um processo de estruturação. Conforme explicam DiMaggio e Powell (1983), num campo esse processo é caracterizado pela tendência ao isomorfismo estrutural, decorrente do aumento da interação entre organizações e do volume de informações com as quais elas devem lidar, do desenvolvimento de estruturas de dominação e de padrões de coalizão interorganizacionais, e do reconhecimento mútuo entre organizações de que estão envolvidas em um empreendimento comum.

Assim, em termos da sua abrangência, campos organizacionais não devem ser tratados simplesmente como construtos agregativos, mas como construtos significativos para os atores envolvidos (DiMaggio, 1991), com fronteiras definidas pelo modo como são percebidas por eles, o que, no nível da ação, afeta não somente as práticas organizacionais como a própria representação do campo. DiMaggio (1991) exemplifica o uso dessa perspectiva em pesquisa realizada acerca do desenvolvimento do campo de museus de arte norte-americanos, no período de 1920 a 1940. Mazza e Pedersen (2004) também adotam essa perspectiva em estudo recente sobre o desenvolvimento do campo da imprensa de jornais e revistas na Itália e na Dinamarca.

\section{Campo como Arena Funcionalmente Específica}

Compreender campo organizacional como a totalidade dos atores relevantes gera uma questão de difícil solução para a análise institucional: a de definição de fronteiras. Esse problema é inerente à própria definição de campo, já que se admitem determinados aspectos constituintes: o reconhecimento por parte dos atores da relevância das relações, a existência de um sistema multidimensional de relacionamentos (ambiente de respostas a respostas), a constituição mútua de atores e de relações numa dinâmica de estruturação, entre outros.

As inúmeras dificuldades de operacionalização têm levado alguns pesquisadores, tais como Scott e Meyer (1983, 1991) e Scott (1991), a optarem pelo resgate da análise de organizações de uma mesma função, o que representa uma demarcação arbitrária das fronteiras do campo. Enquanto recurso tal opção pode auxiliar no sentido de tornar a pesquisa mais factível; todavia, ela torna arriscado atribuir a qualquer campo pesquisado o status real de campo organizacional, pois pressupõe contemplar a sua totalidade. 
É nesse sentido que Scott $(1991,2004)$ sugere o conceito de setor societário; mais tarde o reformula para campo organizacional funcional. Um setor societário é um "conjunto de organizações operando num mesmo domínio, identificadas pela similaridade de seus serviços, produtos ou funções, junto com aquelas organizações que influenciam criticamente o desempenho das organizações focais" (Scott, 1991, p. 117). O adjetivo societário indica a desregionalização da fronteira, não definida geograficamente, mas funcionalmente (em torno de alguma atividade específica), considerando elementos do ambiente técnico e institucional na definição das características do setor, bem como as relações entre essas características e as propriedades das organizações que nele operam, as quais podem ser funcionalmente diferenciadas. Nessa linha de análise, tal conceito é mais abrangente do que a noção de indústria, que sugere o foco em torno de uma atividade econômica específica, e também do que a noção de campo interorganizacional identificada por Warren (1967), ampliando o escopo dos padrões horizontais e verticais de relacionamento entre organizações. Logo, um campo organizacional funcional é um conjunto de "organizações similares e diferentes, interdependentes, operando numa arena funcionalmente específica em associação com seus parceiros de troca, fontes de financiamento e reguladores" (Scott, 2004, p. 9).

Embora não represente a totalidade do campo, essa perspectiva tenta manter coerência com a lógica conceitual proposta por DiMaggio e Powell (1983). Além disso, ela apresenta algumas vantagens para a realização da análise, pois delimita o ambiente de uma organização cuja estrutura ou desempenho está sendo avaliado sob a ótica institucional e define uma unidade intermediária mais factível de ser empregada em análise macrosociológica. No entanto, a definição do grau de relacionamento para consideração de um ator num campo, a especificação de um critério para avaliação da similaridade funcional, a delimitação e o acesso a padrões culturais e a diversidade de campos em que uma mesma organização pode participar são algumas das dificuldades metodológicas que permanecem presentes e que podem limitar as possibilidades de pesquisa sobre campo organizacional (Scott, 1991). Um estudo interessante sob essa ótica é o de Scott, Mendell e Pollack (2000) acerca do campo de assistência médica, no qual eles abordam as lógicas de ação, esquemas de troca, variações no relacionamento e não somente organizações isoladas, mas diferentes populações e conjuntos organizacionais pertencentes ao setor.

\section{Campo como Centro de Diálogo e de Discussão}

Uma terceira acepção de campo organizacional está associada à noção de temática ou assunto, quiçá evento. Em estudo sobre ambientalismo, Hoffman 
(1999) propõe que "um campo deveria ser pensado como centro de canais comuns de diálogo e discussão ... que reuniria vários constituintes do campo com propósitos díspares" (p. 4). Nessa perspectiva, a atenção é direcionada para um tema central com potencial para colocar em debate diferentes agentes, em geral organizados coletivamente sob a forma de coalizões, que não compartilham necessariamente um diálogo isomórfico, expresso em uma retórica comum, mas, ao contrário, disputam interesses díspares, porém relevantes para o alcance dos seus objetivos específicos. Por conseguinte, o campo resulta da negociação por interpretações acerca dos elementos constituintes do tema central em questão, ou seja, de sua estrutura institucional (Hoffman, 1999, 2001).

Para Hoffman (1999) a ênfase em temáticas possibilita uma abordagem mais complexa do que a de redes para explicar a formação e o desenvolvimento de um campo, e também não compromete a lógica conceitual da definição original de DiMaggio e Powell (1983). A estrutura de um campo passa a ser organizada à medida que aumentam as interações e a troca de informações entre certas organizações, e elas passam a se reconhecerem como participantes de um mesmo debate, mesmo que isso não implique em um padrão tangível de relacionamento.

Nesse sentido, Zietsma e Winn (2005) explicam que a definição de campo organizacional com base em temáticas permite a análise da sua dinâmica e da mudança ao longo do tempo. No entanto, os autores alertam que em campos mais estáveis, onde a contestação por temáticas não é intensa, em face da ocorrência de uma lógica institucional mais bem definida e legitimada, sua aplicabilidade é dificultada. Dessa forma, eles sugerem que a definição de campo deva considerar tanto aquelas organizações mais intensamente envolvidas no debate como aquelas preocupadas com a produção e a reprodução de um conjunto específico de práticas ou de arranjos institucionais relacionados à temática em pauta.

Subjacente a tal análise está a consideração de que um campo organizacional é entidade dinâmica, constituída como arena de poder, onde a disparidade de interesses no debate acerca dos temas em questão está presente durante sua estruturação (Brint \& Karabel, 1991). Certo desacoplamento estrutural com os padrões institucionais é admitido no sentido de revelar maior grau de autonomia dos atores sociais na busca dos seus interesses. Ao que nos consta, esta definição de campo organizacional supõe uma perspectiva de economia política conectada a uma visão pluralista do poder.

\section{Campo como Arena de Poder e de Conflito}

Uma quarta perspectiva sobre campos organizacionais baseia-se em Bourdieu, especialmente na sua idéia de que a categoria central para a compreensão das 
relações entre os agentes nos campos sociais é o poder e a sua reprodução. Como explica Everett (2002), nessa ótica, "quando se pensa em termos de campo, deve-se focar em poder, dominação e classe" (p. 60).

Segundo a leitura de Vieira e Carvalho (2003), o campo é então resultado da disputa de organizações pelo seu domínio, numa dinâmica pautada pela (re)alocação de recursos de poder dos atores e de sua posição relativa no que concerne a outros atores. Similarmente, Leão (2001) localiza as organizações num campo de poder entendendo que essa estrutura determina valores e crenças num campo organizacional. Assim, assume que as organizações operam num espaço social de lutas e de relações de dependência, onde interesses implícitos nos discursos e ações empreendidas, recursos sob domínio de determinados atores, bem como regras socialmente aceitas, definem o jogo por controle daqueles recursos do qual decorre a dinâmica de estruturação do campo. Como afirma o autor, "faz-se necessário que se compreendam os atores sociais envolvidos, seus objetivos e pressupostos ideológicos, bem como sua atuação ao longo do processo de constituição do campo" (Leão, 2001, p. 9).

De acordo com essa perspectiva, a mudança ocorre quando os arranjos de poder no campo se modificam e geram novas instituições, o que a distingue das demais pela consideração do poder como elemento causal central na formação de um campo organizacional, e do qual é dele estruturalmente dependente. Nesse sentido, tal abordagem aponta a pouca visibilidade dessa categoria nos estudos institucionalistas que, segundo sua crítica, deveriam analisar "posições dos agentes em campos construídos por disputas entre detentores de recursos de poder, como condição essencial para compreender a dinâmica dos campos organizacionais, entendidos, agora, como espaços de força e de lutas" (Misoczky, 2003, p. 170).

\section{Campo como Esfera Institucional de Interesses em Disputa}

Esta versão de campo organizacional está associada com a abordagem institucional da maneira como é tratada por representantes da sociologia econômica, embora não seja de sua exclusividade. Assim como a anterior, esta perspectiva atribui relevância à noção de campo social de Bourdieu, tanto pelo reconhecimento da dimensão relacional como por sua associação com a idéia de poder e interesses (Swedberg, 2004a, 2004b). Porém, embora esses estudos nitidamente enfatizem aspectos políticos do processo de institucionalização, seus autores parecem amenizar o caráter determinista da estrutura de poder. Desta forma, optou-se por classificá-los como categoria distinta, à medida que sugerem atenção a aspectos mais ativos dos atores, isto é, suas capacidades e ações criativas associadas à atuação deles sobre a ordem institucional em busca de seus interesses. 
Os trabalhos de Fligstein $(1991,1999,2001)$ representam bem essa perspectiva. Segundo o autor, a noção de campo tem a ver com a forma pela qual ordens locais, entendidas como padrões de interação que se reproduzem na ação, são estabelecidas, mantidas ou transformadas. Para ele, a construção de campos organizacionais é fenômeno cultural que envolve práticas sociais preexistentes, regras imersas nas relações de poder entre grupos e estruturas cognitivas que funcionam como quadros culturais (habitus). Tais elementos operam, conjuntamente, como definidores do contexto das ações coletivas. Entretanto, por se tratarem também de sistemas de poder, campos atuam sobre a capacidade de interpretação dos atores, não somente por meio do quadro cultural mencionado, mas também pelas posições ocupadas por diferentes atores, às quais influenciam seus propósitos e seus interesses. Sob essa ótica, atores dominantes (incumbent actors) reforçam suas posições por meio da habilidade de influenciar as regras mediante as quais o campo é estruturado. Essas regras, que constituem o que Fligstein chamou de concepção de controle, operam como um quadro cognitivo para atores e organizações, refletindo o entendimento que possuem da constituição do próprio campo, bem como o sentido que atribuem ao movimento de outros atores e organizações. Por conta disso, campos organizacionais contêm toda informação relevante a partir do ponto de vista dos atores numa dada organização, mas sem caracterizar a determinação estrutural da ação ou o desprezo à capacidade de interpretação dos atores sociais (Fligstein, 1991).

Como se pode notar, mais do que atribuir importância à scripts e normas sociais, Fligstein $(1999,2001)$ sugere atenção à ação estratégica em campos organizacionais, apresentando, para isso, o conceito de habilidades sociais (social skills). De acordo com o autor, trata-se da habilidade de promover cooperação entre atores, no sentido de criar, contestar e reproduzir regras de interação em favor de seus interesses. Logo, campos organizacionais seriam construções produzidas por organizações detentoras de poder, que possuem habilidades sociais e recursos para influenciar as regras de interação e de dependência em função dos seus interesses, que, por sua vez, são reflexos da sua posição na estrutura social do campo. Organizações podem controlar campos organizacionais por meio do seu tamanho relativo em relação às demais no campo e pelo benefício alcançado por seus membros na formação de regras estáveis que regem as ações legítimas no campo, o que tem relação com a abordagem institucional baseada em interesses descrita por Swedberg (2004b).

Outro autor que parece concordar com essa abordagem é Jepperson (1991), ao entender que a ação está associada ao desvio do padrão institucional e não à participação em sua reprodução, de modo que o processo de institucionalização não se opõe claramente aos interesses dos atores. Nessa mesma linha, Lawrence e Suddaby (2005) apresentam o termo trabalho institucional (institutional work) 
como categoria que representa a formulação de ações intencionais para a criação, a manutenção ou a ruptura institucional que, no caso de campos organizacionais, expressam a disputa constante por suas fronteiras.

Hensmans (2003) e Washington (2004) afirmam que esta perspectiva políticocultural resgata elementos que não estariam suficientemente tratados, como a qualidade estratégica da agência de atores-chave na dinâmica de estruturação de campos organizacionais. Tal abordagem estaria apoiada na capacidade de determinados atores em mobilizar diferentes lógicas e recursos para atender aos seus interesses, em consonância com as observações de Seo e Creed (2002) a respeito do processo de mudança institucional.

\section{Campo como Rede Estruturada de Relacionamentos}

Um campo, conforme afirmam DiMaggio e Powell (1983), define uma reconhecida área de atividade social ou econômica, na qual os atores estabelecem relacionamentos entre si, reconfigurando seus modelos de ação e a estrutura social. As organizações e outros atores sociais não estão envolvidos somente em relações de trocas, mas se posicionam em uma estrutura de relacionamentos, ou rede, que configura suas ações e delimita suas possibilidades (DiMaggio, 1991; Scott, 1991).

Com base nesses aspectos, diversos estudos têm procurado analisar o conceito de campo sustentado na noção de rede social. Powell, White, Koput e OwenSmith (2005) afirmam que

Esta ligação entre a dinâmica de redes e o desenvolvimento da estrutura dos campos deve ser realizada de modo a contribuir para a explicação de como o comportamento de atores ou organizações de um tipo influencia as ações de organizações de outro tipo (p. 4).

Mohr (2000) considera que o conceito de campo, desde a sua formulação por DiMaggio e Powell (1983), traz uma metáfora de espaço topológico onde ocorre a interação, o que naturalmente tem atraído o interesse em estudos de redes interorganizacionais, embora remeta a uma questão relevante: a representatividade do campo por meio da análise de redes.

Nessa perspectiva, campos seriam redes de relacionamentos, "que emergem como ambientes estruturados e estruturantes para organizações e participantes individuais" (White, Owen-Smith, Moody, \& Powell, 2004, p. 97), estando normalmente organizados de modo mais integrado e entrelaçado, e podendo ser desvendados por estudos topológicos e de coesão estrutural. A sua definição parte do mapeamento empírico de determinadas condições estruturais a partir 
das quais argumentos institucionais podem ser utilizados para complementar a sua identificação.

A noção de campo como rede de relacionamentos permite resgatar o papel dos atores e sua capacidade de agência no processo de estruturação. Estudos mais recentes (Powell et al., 2005; White et al., 2004) com base nessa perspectiva procuram entender a mútua influência entre a estrutura e a dinâmica do campo mediante a análise de sua configuração em diferentes momentos do tempo e sua influência sobre as decisões para os atores envolvidos. A configuração relacional entre atores influencia os parâmetros para as decisões subseqüentes e para a própria trajetória do campo. Contudo, apesar da importância dos estudos longitudinais sobre configurações estruturais, o foco na dimensão relacional não pode implicar em abandono da dimensão simbólica. Vale destacar que os conceitos de simultaneidade e de recorrência não se restringem a relacionamentos, mas se estendem também para a noção dos significados espaciotemporalmente delimitados.

\section{Breves Considerações sobre as Perspectivas Teóricas}

Verificamos que do conceito formulado originalmente por DiMaggio e Powell (1983) às versões subseqüentes, certos aspectos são recorrentes, enquanto outros são específicos de determinada linha de investigação. As diferentes alternativas conceituais apresentadas sugerem não somente variedade de ênfases sobre o entendimento do campo organizacional, como também preferências teóricas e particularidades analíticas, que, em certos casos, não são excludentes entre si.

De comum entre elas, o que se percebe é a tendência em destacar mais acentuadamente no campo organizacional a dimensão relacional/estrutural do que a dimensão simbólica/de-significado, o que, em certa medida, pode decorrer da própria definição estabelecida por DiMaggio e Powell (1983). Nela, está evidente a referência à noção de campo enquanto espaço comunicativo entre diferentes atores sociais, que delimita valores, normas sociais, sanções e outros aspectos, em decorrência da configuração relacional entre eles (Mohr, 2000). Em termos práticos, a dimensão simbólica de um campo combinada com sua faceta material, sob a ótica dos atores, acaba por definir uma arena de interação da qual deriva sua noção de posição no campo, entendida como sua referência em relação aos demais atores (sense of one's place and other's place), bem como seus parâmetros para a ação.

Enquanto espaço articulado de relações, a noção de campo favorece uma abordagem mais estrutural, fundamentada na análise de padrões e intensidade de relacionamento. No entanto, um dos aspectos que procuramos salientar ao 
longo do artigo é o fato de que, além da consideração material das relações entre atores, a ordem simbólica acerca do significado dessas relações precisa ser observada. Em qualquer explicação da ação coletiva, fins racionais não possuem sentido sem que se considere categorias culturais, como valores e crenças, localizadas em um determinado contexto histórico. As redes sociais devem ser entendidas também como entidades fenomenológicas, uma vez que constituem redes de significados (Emirbayer \& Goodwin, 1994; Friedland \& Alford, 1991).

No que tange à constituição de um campo organizacional, há sempre um conjunto de pressupostos a respeito da sua estruturação, entre os quais se destacam os de duas abordagens: uma delas sustentada em Bourdieu e a noção de campos sociais; outra, em Giddens. Ambas estão presentes já na base do conceito de campo organizacional de DiMaggio e Powell $(1982,1983)$. As duas pressupõem a análise da dualidade/dualismo entre significado e estrutura social. No entanto, embora possuam aspectos em comum, suas premissas não são equivalentes (Mohr, 2000). Um dos pontos de distinção entre elas está na forma como o poder, o conflito e a posição social se apresentam no processo de estruturação.

Bourdieu $(1989,2003)$ considera que as relações de poder estruturam a sociedade e estão na essência da disputa por capitais por parte de atores que desejam sustentar ou transformar a sua posição ou a estrutura social em determinado campo, influenciando o significado das relações que lhes garantem legitimidade. Já em Giddens (1978, 2003) a dinâmica social é diferentemente tratada, sendo poder e posição social vinculados à prática, não no sentido de competência estratégica, mas enquanto parte de dimensões de interação. Assim, a noção de estruturação representa a contínua reprodução/reconstrução da estrutura social por atores reflexivos em contextos de tipificação de práticas. É interessante notar que, mesmo sendo frequentemente citada como fundamental para a abordagem cultural-cognitiva do institucionalismo, tal idéia de estruturação ainda tem sido pouco explorada no sentido de definir os contornos de uma articulação teórica e empírica que melhor estabeleça um quadro analítico para o estudo de campos organizacionais (Frumkin \& Kaplan, 2000; Munir, 2005).

No contexto acadêmico brasileiro, o que se pode notar acerca dos estudos em campos organizacionais é a referência a três autores centrais: DiMaggio, Scott e Bourdieu, sendo este último o de maior destaque. Na Figura 1 representamos o relacionamento entre 25 artigos analisados e autores referenciados por eles em sua conceituação de campo organizacional. Esses artigos foram selecionados em periódicos nacionais classificados como conceito A ou B pela Capes, e em anais das diversas edições do EnANPAD e do EnEO, no período de 1998 a $2005^{(3)}$. 


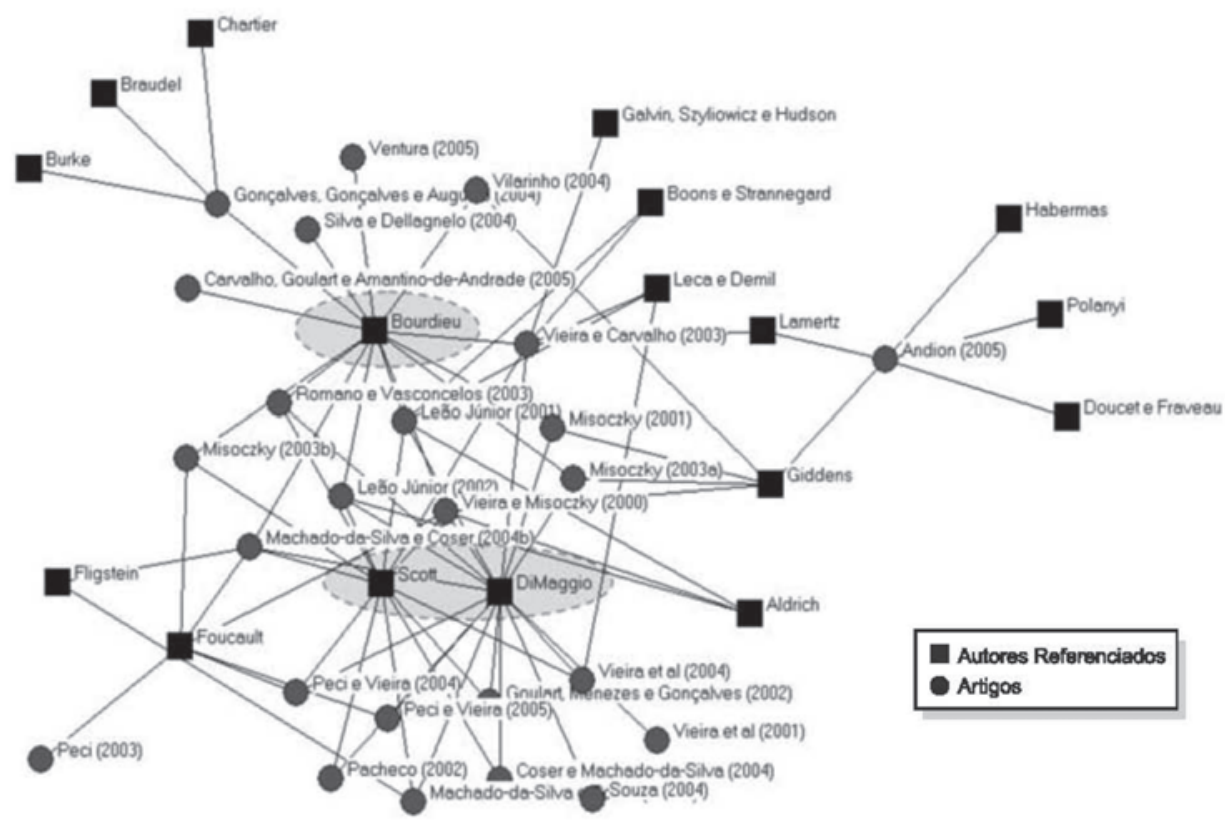

Figura 1. Rede de Artigos x Referências (*)

(*) Não se considerou a polaridade da relação, em que se indicasse se as idéias de determinado autor são positiva ou negativamente tratadas no artigo selecionado.

Fonte: Artigos publicados em periódicos nacionais e em anais do EnANPAD e do EnEO, de 1998 a 2005.

Observou-se que num total de 149 referências sobre campo, Bourdieu foi citado 46 vezes (30,9\%), DiMaggio 33 vezes (22,1\%), e Scott 25 vezes (16,8\%). Os três autores juntos somam 104 referências, ou seja, $69,8 \%$ de todas as referências sobre campo foram atribuídas a eles, corroborando a centralidade visível na rede exposta na Figura 1.

Embora alguns estudos tenham se reportado principalmente à abordagem de campo como a totalidade dos atores relevantes (Coser \& Machado-da-Silva, 2004; Machado-da-Silva \& Coser, 2004a, 2004b), com base essencialmente no trabalho de DiMaggio e Powell (1983), verificamos que os autores nacionais recorrem principalmente aos textos de Bourdieu (1983, 1990, 1992, 1996, 2003, 2004) e de Bourdieu e Wacquant (1992) para a construção do conceito de campo, servindo também como arcabouço analítico. Essa preferência dos pesquisadores favorece a abordagem apoiada na visão de campo como arena de poder e de conflito, que se destaca no contexto brasileiro.

Para Bourdieu (2003) o poder é variável central nas lutas de interesses dentro de um campo. O campo é entendido enquanto configuração de relações entre posições 
objetivamente definidas, na sua existência e nas determinações que impõem sobre seus ocupantes, agentes ou instituições, por sua situação presente e potencial na estrutura de distribuição dos tipos de poder (ou capital), cuja posse comanda o acesso aos lucros específicos que estão em jogo no campo, bem como pela relação objetiva com outras posições (dominação, subordinação, etc.) (Bourdieu \& Wacquant, 1992, p. 97).

Assim, um campo é considerado um espaço estruturado de posições, uma arena de disputa por legitimação, em que agentes lutam pela redefinição ou apropriação de um capital específico desigualmente distribuído. Essa desigualdade define a estrutura do campo, onde se encontram dominantes e dominados, e reflete uma relação de forças historicamente engendradas por um sistema de disposições incorporadas, que não só possibilita a ação nesse jogo como também o reconhecimento da sua importância, numa espécie de cumplicidade objetiva para além das lutas e em favor da própria existência do campo (Lahire, 2002).

Na visão de Thiry-Cherques (2006), Bourdieu tem como objeto de investigação conhecer as estruturas no sentido de que elas determinam as relações internas a um segmento do social, ao tempo em que são determinadas por essas relações, isto é, são estruturadas. Afirma o autor que Bourdieu segue, em linhas gerais, o protocolo de investigação estruturalista, mas tem como fundamento epistemológico o materialismo racional de Bachelard.

Bourdieu (1985, 1989, 2003), no entanto, define sua abordagem como construtivista estrutural ou estruturalista construtivista, significando o entendimento de que ela está organizada de modo a superar a dicotomia entre objetivismo e subjetivismo. Entende que a análise sociológica precisa levar em conta dois momentos complementares. No primeiro deles, interessa a análise do espaço social, considerando a posição relativa e as relações objetivas entre os agentes, na qual se admite que a diferenciação depende do volume de capital de posse do agente. À medida que se torna mais claro o tipo de capital que define as posições, delimita-se também uma espécie de campo de poder, e disso decorre o papel ativo dos tipos de capital e das lutas políticas como propriedades ativas na construção do espaço social. Por outro lado, o segundo momento da análise sociológica deve tratar da percepção social do mundo, na qual a noção de habitus é relevante, expressando por meio de esquemas de percepção e de apreciação a posição social em que foi elaborado. Conforme explica, o habitus é produto da internalização de estruturas, configurando esquemas mentais para a apreensão do mundo. "Temos inscrito em nós, os princípios geradores e organizadores das nossas práticas e representações, das nossas ações e pensamentos. ... Percebemos, pensamos e agimos dentro da estreita liberdade, dada pela lógica do campo e da situação que nele ocupamos" (Thiry-Cherques, 2006, p. 34). Isso 
coloca o habitus como mecanismo de reprodução social, cujo grau de abertura para a mudança é ponto controverso entre os cientistas sociais (vide: Lau, 2004; Lizardo, 2004). Contudo, para Lizardo (2004) não há nada no conceito de habitus que impossibilite o seu uso de modo não-determinista. Ele afirma que muitos críticos atacam a força do habitus na reprodução social, mas ignoram a possibilidade da sua utilização de forma mais flexível, ensejando ações propositadas e criativas.

Já Everett (2002) entende que certo determinismo social está imbricado na perspectiva de Bourdieu. Os atores têm pouca liberdade de ação, delimitados por estruturas sociais, com pouco espaço para a reflexividade e para a mudança. Ademais, ele identifica problemas na universalização da noção de classe de Bourdieu, que funde o conceito de classe econômica de Marx e de status de grupo de Weber. O autor questiona, ainda, a fragilidade na limitação de um campo, pois dificilmente se sabe o que está ou não ao alcance de suas fronteiras. Afirma que na abordagem de Bourdieu: (i) a análise das estruturas objetivas são logicamente conduzidas pela análise de disposições objetivas, (ii) e essa relação preenche funções políticas, o que torna os sistemas simbólicos instrumentos de dominação; e (iii) sistemas simbólicos são produtos sociais que constituem relações sociais, passíveis de transformar a representação no mundo, revelando relações sociais de poder vinculadas a bens simbólicos que contribuem para a reprodução ou transformação de estruturas de dominação.

Em linha de análise correlata, Warde (2004) constata certa dificuldade em se identificar a atividade que fornece o conteúdo, a razão de ser, para a existência de um campo. Segundo ele, a associação de determinadas práticas, geralmente concebidas como atividades típicas, desempenhadas e imbricadas no habitus, ao conteúdo existencial de um campo deixa de lado aspectos relevantes da dinâmica institucional. Por entender que esse conceito de campo padece de um enfoque excessivamente estrutural, propõe a sua revisão. Considera que para a sua efetiva compreensão é necessário o reconhecimento tanto do nível de institucionalização do campo em si, associado à estrutura relacional fundada sobre a ação estratégica pela disputa de capital como da institucionalização de práticas, tratadas de modo mais amplo como entidades coordenadas, existentes por meio do seu desempenho efetivo na ação, e resultantes de processos históricos de interação social, variáveis no espaço-tempo. Argumenta que, na abordagem de Bourdieu, toda conduta relevante para a investigação sociológica é estratégica e competitiva de tal modo que a análise de campos sociais não possibilita a apreciação de uma ampla teoria de práticas. Além disso, pode-se sugerir que essa abordagem tende a privilegiar a competência de agentes mais poderosos e estruturalmente melhor posicionados na luta para assegurar a sua legitimidade e o domínio do campo. 
No contexto acadêmico brasileiro, Machado-da-Silva, Fonseca e Crubellate (2005) consideram que o problema de algumas formulações, apoiadas em certas leituras de Bourdieu, está na concepção do poder como fundamentalmente vinculado à "perspectiva única da intencionalidade, [o que a] torna próxima do pressuposto racionalista; pelo menos no que toca à sua subjacente orientação voluntarista" (p. 17). Assim, relações sociais no campo assumem uma forma mecanicista, que se apóia estritamente na funcionalidade dos relacionamentos.

\section{Giddens e a Teoria da Estruturação}

A teoria da estruturação, conforme apresentada por Giddens (1978, 2001, 2003), focaliza sua atenção primordialmente no aspecto ontológico, procurando superar o dualismo por muito tempo presente na teoria social no que se refere às concepções de ser humano, fazer humano, reprodução social e transformação social. Esse dualismo é marcado, essencialmente, pela polarização entre objetivismo e subjetivismo, reconsiderado na teoria da estruturação enquanto dualidade da estrutura: "as propriedades estruturais dos sistemas sociais só existem na medida em que formas de conduta social são cronicamente reproduzidas através do tempo e do espaço" (Giddens, 2003, pp. XXII-XXIII). Cohen (1999) explica que a teoria da estruturação representa uma visão pós-empirista, sem a pretensão de universalizar qualquer conjunto de práticas ou processos de (re)produção social, mas de (re)formular seus potenciais constitutivos. Nesse sentido, a exposição de seus componentes principais se faz necessária para o entendimento dos argumentos sobre campos organizacionais que serão apresentados na seqüência.

A chave para a compreensão da teoria da estruturação está no conceito de (re)produção social, contrariando a teleologia funcionalista e a dicotomia entre estática e dinâmica. Nesse sentido, qualquer situação social é considerada

uma realização contingente de atores sociais e ... uma hábil produção que se sustenta sob as condições da racionalização reflexiva da ação ... porquanto todo ato de reprodução é, ipso facto, um ato de produção, em que a sociedade se recria num novo conjunto de circunstâncias (Giddens, 2001, p. 152).

Sob essa perspectiva, Giddens (2003) entende que sistemas sociais são "relações reproduzidas entre atores ou coletividades, organizadas como práticas sociais regulares" (p. 29). Como tal, Giddens (2001) lhes atribui caráter pessoal e espaciotemporal na medida em que são continuamente criados e recriados como realização ativa de sujeitos. Whittington (1992) reforça que o conceito de sistema 
social suspende o dualismo entre estrutura e agência, criando uma dualidade interdependente. Nessa perspectiva, a análise do processo de estruturação só é possível com o estudo das atividades dos atores, que são apoiadas pelas regras e recursos disponíveis em seu contexto de ação. Grupos e coletividades devem ser vistos como sistemas de interação, onde os atores produzem e reproduzem tal contexto, reformulando continuamente os sistemas sociais (Giddens, 1978). Assim, entende-se como estruturação "a reprodução de práticas, ... ao processo dinâmico pelo qual as estruturas passam a existir" (Giddens, 1978, p. 129), o que está intimamente relacionado à dualidade da estrutura na interação social.

Portanto, estrutura é concebida como "regras e recursos gerativos que tanto se aplicam à ação como se constituem a partir dela" (Giddens, 2001, p. 145), num processo de estruturação que se estende ao longo do tempo e espaço, envolvendo a comunicação do significado (regras semânticas), o exercício do poder (recursos desigualmente distribuídos) e a avaliação da conduta (regras morais ou normativas). Sob esse prisma, regras e recursos são propriedades de coletividades, expressas na produção da interação social, respectivamente, enquanto estruturas de significação, dominação e legitimação (Bryant \& Jary, 2001; Giddens, 1978). Conforme explica Giddens (2003),

dizer que estrutura é uma ordem virtual de relações transformadoras significa que os sistemas sociais, como práticas sociais reproduzidas, não têm estruturas, mas antes exibem propriedades estruturais, e que a estrutura só existe, como presença espaço-temporal, em suas exemplificações em tais práticas e como traços mnêmicos orientando a conduta de agentes humanos dotados de capacidade cognoscitiva (p. 20).

Entretanto, considerar estruturas como conjunto de regras e recursos requer atenção especial. As regras da vida social devem ser vistas como técnicas ou procedimentos generalizáveis aplicados no desempenho/reprodução de práticas sociais, expressando-se no âmago da cognoscitividade dos agentes humanos, sobretudo na consciência prática e, de certa forma, envolvidas na manutenção da segurança ontológica dos agentes, pois são usadas na constituição e reconstituição de encontros (Giddens, 1978, 2003). Recursos, por sua vez, são bases acessíveis de poder que fornecem os meios para influenciar o curso de interação entre os agentes, mas que não estão descolados dos aspectos semânticos e morais (Cohen, 1999). Assim, estruturas são ao mesmo tempo meios e recursos para a reprodução do sistema, estando associadas à aspectos da prática rotineira, à constituição de significados e à sanções localizadas em circunstâncias históricas e espaciais determinadas.

Em relações sociais, consideram-se tanto a padronização de interações sociais no tempo-espaço e na reprodução de práticas localizadas como uma ordem virtual 
de estruturação recursivamente implicadas nessa reprodução. A estrutura, portanto, não deve ser equiparada à coerção, pois ela é, simultaneamente, facilitadora e restritiva, não possuindo existência independente do conhecimento dos atores sociais a respeito do que fazem em sua atividade cotidiana, mas "de-sujeitificada nas práticas de uma coletividade" (Bertilsson, 1984, p. 343). Em tempo, Giddens (2003) chama de integração social aquela ocorrida entre atores em contextos de co-presença, onde há reciprocidade entre práticas, e integração de sistema as conexões entre atores que estão fisicamente ausentes espaciotemporalmente.

Mais do que isso, a contextualidade espaciotemporal deve ser reposicionada na teoria. Para melhor compreender esse aspecto é preciso reconhecer que sujeitos são antes de tudo agentes. Isso indica que há um quadro de ação prática na conduta humana que nem sempre pode ser colocado em palavras, o que não significa que não seja feito (praticado). Assim, o pressuposto do sujeito cognoscitivo, que monitora reflexivamente suas ações no sistema social, também considera que parte dessa monitoração não é discursada, mas conformada como consciência prática, não verbalizada, e por si só parte do próprio conjunto de ações. Nesse ponto, Cohen (1999) explica que "a qualidade característica da consciência prática é que os agentes precisam estar apenas tacitamente cônscios das habilidades que eles vieram a dominar, embora seja geralmente possível concentrar a atenção discursiva quando surge uma ocasião para tal" (p. 413). Ou seja, os agentes possuem uma forma de conhecimento essencialmente tácito que os orienta no agir ou prosseguir no âmbito das rotinas da vida social. Nesses termos, em se tratando de agentes reflexivos e que se movem espaciotemporalmente, a diferenciação de contextos está associada com a orientação dessas ações. Contextos são como cenários para as ações, aos quais os agentes recorrem para orientar o que fazem e dizem aos outros. Há, portanto, um processo de indexabilidade contextual configurando cenários de ação prática, tipificados e inerentes aos estoques de conhecimento mútuo, que os agentes utilizam para produzir um mundo significativo (Giddens, 1999).

É interessante observar que o conhecimento mútuo, no entendimento de Giddens (2003), pressupõe sua duração para além da biografia de qualquer agente ou grupo de agentes, estendendo-se espaciotemporalmente. Os traços de memória, presentes no processo de estruturação, seriam o instrumento básico pelo qual o conhecimento mútuo é preservado pelos agentes e transportado para as situações onde as práticas respectivas são reproduzidas. Portanto, o conhecimento mútuo, analiticamente, representa aquele conjunto de regras consideradas como propriedades estruturais de caráter semântico e normativo, que, associadas a recursos, enquanto meios pelos quais essas regras são aplicadas, compõem às dimensões da dualidade da estrutura (Cohen, 1999). Isso, entretanto, não quer 
dizer que na teoria da estruturação se aceite o princípio de uniformidade de práticas sociais. Conforme observa Cohen (1999),

na teoria da estruturação, os tipos de recursos aos quais os agentes têm acesso e as habilidades cognoscíveis envolvidas nas práticas que eles desempenham, assim como o seu conhecimento discursivo de condições sociais mais amplas, sempre existem no interior de limites históricos e espaciais determinados ... A variabilidade histórica da práxis social em termos ontológicos... refere-se apenas aos aspectos de um objeto que existe onde quer que ele seja encontrado... A teoria da estruturação fornece uma ontologia dos potenciais. Ela sustenta que um potencial possuído pelos agentes sociais é a capacidade de produzir variações históricas em suas próprias formas de conduta (p. 416).

Essa capacidade tem relação com o poder subjacente à ação humana, o poder de fazer uma diferença. Ação é equiparada a capacidade transformativa na teoria da estruturação (Cohen, 1999). Nesse sentido, mesmo que a vida cotidiana envolva uma seqüência de ações intencionais, esses atos produzem conseqüências imprevistas que sistematicamente podem realimentar-se na constituição de condições não reconhecidas de novos atos.

\section{Teoria da Estruturação e Campos Organizacionais}

Apesar de Giddens não fazer menção a campo organizacional como conceito ou unidade de análise no momento em que trata de sistemas sociais e sua multiplicidade, suas idéias possibilitam enquadrar a análise de campos numa estrutura analítica apoiada na ótica da teoria da estruturação. Sistemas sociais referem-se às atividades dos agentes humanos, reproduzidas em práticas localizadas, mas também à padronização de relações sociais ao longo do espaço-tempo, podendo ser entendidos como nível intermediário entre agentes e sociedade, onde se fazem presentes as dimensões de interação social (poder, sanções e formas de comunicação). Assim, "analisar a estruturação de sistemas sociais significa estudar os modos como tais sistemas, fundamentados nas atividades cognoscitivas dos atores localizados, que se apóiam em regras e recursos na diversidade de contextos de ação, são produzidos e reproduzidos em interação" (Giddens, 2003, pp. 29-30). Considerando que, em campos organizacionais, agentes interagem entre si (re)produzindo estruturas sociais por meio de modalidades de estruturação, algumas considerações a esse respeito se fazem necessárias.

A idéia de estrutura em interação nos sistemas sociais é oportuna para um entendimento dinâmico da noção de poder, o que parece ser mais adequado às 
idéias até aqui delineadas, pois, ao contrário do que sugerem algumas leituras sustentadas em Bourdieu, poder não é tratado de forma mecanicista ou como fim para os participantes de um campo. Segundo Giddens (2003), se o poder tem ou não ligação com interesses seccionais distintos, isso não equivale à sua definição. Dessa forma, o poder não é visto como obstáculo a liberdade; entretanto, seu caráter coercitivo não pode ser ignorado. O poder como dimensão de interação supõe que estruturas de dominação sejam reproduzidas no tempo e no espaço. Porém, como abordado anteriormente, estruturas de dominação estão imbricadas em estruturas de significação e legitimação, ou seja, não surgem no vácuo como produto restrito de posições sociais, mas como meio e produto da construção de significado e de legitimidade em contextos de interação. Esse tipo de formulação pressupõe necessariamente uma dialética de controle em que a geração de poder não é exclusiva de grupos dominantes. É um efeito do relacionamento e da situação compartilhados entre dominantes e dominados (Bryant \& Jary, 2001).

A dualidade entre estrutura e agência permite entender que campos são sistemas relativamente fechados, o que não implica afirmar que sejam socialmente coesos, cuja dinâmica de interação, embora pautada por referências estruturais localizadas, não possibilite a criação de novos padrões. No entanto, falar da dualidade da estrutura como reprodução de propriedades estruturais a partir da práxis de atores cognoscitivos, é aceitar que eles são capazes não só de reproduzir, mas de produzir novos padrões de interação, alterando endogenamente a estrutura do campo. Acredita-se que, nesse sentido, a teoria da estruturação proporciona mais reconhecimento tanto ao agente como ser reflexivo e capaz de ser instrumento de mudança, quanto à prática desses agentes dentro do campo. Entender que somente agentes estruturalmente privilegiados são estratégicos na ação, como é tratado em algumas interpretações de Bordieu, seria tratar a agência de forma estratificada, sendo incoerente com a noção transformadora tratada até aqui.

No que se refere ao campo e sua delimitação, os elementos da teoria da estruturação permitem tecer outros comentários. Partindo-se do princípio de que existem vários campos organizacionais além daquele de interesse para análise, assume-se também que os agentes competentes podem adquirir e usar seu conhecimento em diferentes campos. Dessa forma, a abrangência de um campo organizacional não está restrita a influências endógenas, ou, mais propriamente, a propriedades auto-referentes. Na realidade, pode-se afirmar que, enquanto sistema social, possui uma lógica interna que serve de referência para ações, julgamentos, ponderações e identidade, sem, contudo, lhe conferir autonomia plena ou isolamento de processos sociais mais amplos dos quais faz parte. Assim, integração social e de sistema estão implicadas no processo de estruturação e de análise de campos. 
É necessário, ainda, reconhecer que a dinâmica de relações entre os atores dentro e fora do campo é também simultânea. Ou seja, por estarem em constante processo de estruturação, ações em campos distintos podem convergir simultaneamente, mesmo quando os atores não estão integrados socialmente. As implicações da simultaneidade de ações entre atores de campos distintos podem possibilitar o seu relacionamento em algum momento, consistindo um novo potencial de interações que, ao longo do tempo, pode acarretar um processo de conformação de fronteiras (ou escopo) dos campos iniciais. Nesse ínterim, a falência ou integração de ordens institucionais precedentes é contingente ao próprio processo em curso.

Da mesma forma, na medida em que se tenta estabelecer uma nova ordem legítima sobre a configuração em elaboração, apesar da possibilidade de contradição entre estruturas de campos distintos, necessariamente não ocorrerá conflito. Giddens (1978) explica que a noção de conflito está intimamente ligada a de interesse. Nesse caso, conflito é propriedade de interação, no sentido de luta ativa conduzida no contexto dos choques de interesses. Já contradição pode ser entendida como propriedade das estruturas, e se mantém numa relação contingente ao conflito. É evidente que tais propriedades estruturais acarretam a estratificação de interesses no nível de integração social; porém a ocorrência de conflito não produz necessariamente contradição de sistema, nem a existência dessa contradição se expressa, inevitavelmente, em uma disputa aberta no campo.

Esse aspecto tem implicações contraditórias sobre a perspectiva de campo como arena de poder e de conflito, apresentada em seção precedente. Ao tratar conflito e contradição de forma similar incorre-se em inconsistências analíticas, principalmente quando se afirma que a diferença de posições ocupadas por atores em um campo determina a natureza do conflito entre eles. Contudo, o próprio conceito de posição deve ser visto com ressalvas.

Giddens (2003) observa que "as posições sociais são constituídas estruturalmente como interseções específicas de significação, dominação e legitimação que se relacionam com a tipificação de agentes" (p. 97). Portanto, diante das distinções entre contradição e conflito, é inconcebível aceitar que o conflito entre posições é uma condição sine qua non, bem como aceitar que esses conflitos sejam originados exclusivamente pela disputa de poder entre os agentes, pois, reduzindo-se a totalidade das ações dos agentes somente a disputas pelo poder, ignora-se elementos de significação e legitimação imbricados no processo de estruturação de campos sociais. Conforme explicam Friedland e Alford (1991) "a sociedade é constituída a partir de múltiplas lógicas institucionais" (p. 243), as quais consideram o entrelaçamento dos níveis individual, organizacional e societário, bem como a variação institucional de padrões de relacionamento, tanto na consideração de elementos simbólicos como no reconhecimento de sua 
dimensão material. "Essas lógicas institucionais são simbolicamente definidas, organizacionalmente estruturadas, politicamente defendidas e técnica e materialmente restringidas, e por isso possuem limites históricos específicos" (Friedland \& Alford, 1991, pp. 248-249).

A despeito das referências traçadas até aqui, é pressuposto que campo representa um nível intermediário de estruturação social, considerado elemento mediador entre estruturas sociais e culturais mais amplas e organizações, mesmo que conceitualmente não possua equivalência direta na teoria da estruturação. Nesse sentido, é importante observar que no decorrer das transformações sociais que conduziram à sociedade contemporânea, as organizações assumiram significado substantivo no processo mais amplo de estruturação social. No entanto, conforme observa Ackroyd (2000), por se estar teorizando sobre uma sociedade organizacional, é comum, especialmente em teorias sociais mais recentes, como a de Giddens, a integração, indistintamente, de processos de estruturação societária e organizacional. As implicações a esse respeito são várias, mas pelo menos duas delas merecem destaque: a primeira refere-se ao status ontológico do nível organizacional e sua implicação para a agência e a reflexividade nos processos sociais de estruturação; a segunda diz respeito ao reconhecimento das organizações e, de modo similar, do campo organizacional, como níveis intermediários de estruturação, mediadores das relações mais amplas da sociedade com indivíduos e com as próprias organizações.

Seguindo por essa linha de raciocínio, a exemplo de Chia (2003) consideramos que organizações, mais do que entidades concretas, são world-making, participando do contínuo processo de construção social da realidade por meio da rotinização, formação e institucionalização de normas e códigos de comportamento. Entretanto, contradizendo concepções mais radicais do construcionismo social, elas não podem ser reduzidas meramente a esses padrões definidos de abstração social, incapazes de serem desacopladas do contexto discursivo ou da realidade lingüística em que se situam. Devem também ser tratadas estruturalmente.

Consideradas estruturalmente, explica Ackroyd (2000)(4), as organizações representam contextos para a ação em que são definidos parâmetros para a agência humana efetiva. O nível organizacional é aquele em que a relação entre agência e estrutura é mais visivelmente representada; é onde a "agência corporativa emerge, reproduz e transforma os mecanismos estruturais pelos quais a vida social é coordenada e controlada, estabelecendo graus, sempre contestados, de continuidade e estabilidade" (Reed, 2005a, p. 1635). Segundo este autor, é nesse encontro entre agência e estrutura que são criadas "tensões dinâmicas direcionando cadeias interativas subseqüentes de mudanças sócio-históricas, produzindo conseqüências não intencionadas e não previstas para todos aqueles 
envolvidos" (Reed, 2005b, p. 1669). Nesse nível, as organizações são experimentadas como reais. Ao mesmo tempo em que são ativamente constituídas por seus membros, podendo ser vistas como meios de poder econômico, social e de contestação pela sustentação de determinadas relações sociais, elas também delimitam (constrangem e possibilitam) estruturalmente a participação e a influência dos indivíduos na sociedade. Assim, "contribuem e também alteram a reflexividade de modos que encorajam o engajamento ativo de participantes nos processos organizacionais, mas, ao mesmo tempo, envolvem geralmente um baixo nível de acoplamento afetivo a eles" (Ackroyd, 2000, p. 102).

De modo similar, o conceito de campo é tratado como mediador no processo de constituição organizacional, sendo a estruturação histórica dele considerada logicamente anterior ao de institucionalização de formas organizacionais (Scott, 2001). Nessa ótica, os efeitos sobre os sistemas organizacionais não atuam diretamente; são mediados por processos e estruturas operando ao nível de campo organizacional (Davis \& Marquis, 2005; Scott, Mendell, \& Polack, 2000). Consequentemente, a sua relevância para os estudos organizacionais não é apenas teórica, mas também de ordem prática no processo de estruturação social, apresentando influências causais, porém não deterministas, sobre as organizações ${ }^{(5)}$. Enquanto nível intermediário de estruturação social, conforme Reed (2005a), o campo pode ser concebido como espaço conceitual e domínio ontológico onde mecanismos gerativos subjacentes atuam na (re)constituição organizacional e na (re)produção social. Compreendê-lo sob essa perspectiva não é trivial e, portanto, requer alguns esclarecimentos apoiados na lógica estruturacionista, em que a noção de campo pode fazer referência tanto a processo como a estrutura.

Enquanto sistema social é estrutura por ser constituído previamente, num processo de estruturação que, temporalmente, precede o momento presente. E, dessa forma, representa propriedades estruturais que podem ser reproduzidas e/ ou transformadas, de modo consciente ou tacitamente. Admite-se a existência do campo como fenômeno social independente da sua identificação (transfactualidade). Por assim ser, pressupõe-se a sua historicidade, tanto no sentido dele ser elaborado mediante relações e regras específicas num determinado contexto (path dependence), como também por permanecer dependente de conceitos socialmente construídos na dinâmica social (interpretação).

Evidentemente, a concepção defendida aqui não considera os indivíduos como se fossem culturalmente narcotizados (cultural dopes), mas como agentes cuja temporalidade das ações deve ser contemplada na análise (Acroyd \& Fleetwood, 2000; Schmidt, 1997). Sob essa ótica, verifica-se que o campo possui uma 
influência causal. Ele não é apenas uma representação de estrutura enquanto regras e recursos culturalmente sustentados, mas um sistema de relações e de posições sociais ${ }^{(6)}$ (posição-prática), pré-existente e com potencial para influenciar as ações. Nesse ponto, acredita-se que os relacionamentos num sistema social, uma vez estabelecidos, apresentam influência causal na atenção subseqüente a regras e recursos na estruturação (Mingers, 2003; Porpora, 1998). Em outras palavras, propriedades de interação estão associadas a posições em relacionamentos sociais, que, por sua vez, podem facilitar, restringir ou motivar as ações dos agentes ${ }^{(7)}$. Enquanto estrutura, campos não são considerados epifenômenos do comportamento humano intermediado por organizações, embora sejam recursivamente produto da agência humana. Ou ainda, como explica Reed (2000), "formas organizacionais ... são estruturas em virtude do fato de possuírem propriedades institucionais espacial, temporal e socialmente duradouras que são irredutíveis às atividades de agentes contemporâneos" (p. 57). Nesse sentido, a natureza social do campo é considerada pré-estruturada, caracterizando uma assimetria no relacionamento estruturacionista entre agência e sociedade (Bhaskar \& Lawson, 1998), e, por isso, possuidora de um potencial causal sobre a agência intencional humana e os acontecimentos empiricamente observáveis (Bhaskar, 1998).

Cohen (1999) explica que se trata de uma ontologia de potenciais em que

o elemento ontológico da teoria científica pode ser entendido como uma série de percepções internamente coerentes nos potenciais trans-históricos dos fenômenos que constituem um domínio de investigação, isto é, os processos e propriedades fundamentais que podem ser ativados ou realizados de numerosas maneiras diferentes e em diferentes ocasiões (p. 401).

Ainda segundo o autor, essa visão é compatível com a ontologia estruturacionista, "voltada exclusivamente para os potenciais constitutivos da vida social" (Cohen, 1999, p. 402). Tais potenciais são possuídos, mas nem sempre exercidos pelos agentes sociais, impossibilitando a determinação histórica de eventos e processos.

Nesses termos, a noção de campo também deve ser reconhecida enquanto processo recursivamente estruturado. Agentes não criam o campo a partir do nada. Eles o recriam, reproduzem ou transformam a partir de estruturas pré-existentes que potencializam suas ações. Entretanto, mesmo consideradas pré-existentes, estas estruturas só continuam a existir por meio da reprodução e/ ou transformação de outras estruturas que os agentes encontram em suas ações sociais, numa combinação específica de práxis e estrutura, histórica e temporalmente localizada (Acroyd \& Fleetwood, 2000; Mingers, 2003). 
A capacidade transformativa inerente à lógica da estruturação, na medida em que se admite a reflexividade dos agentes e o nível organizacional como intermediário na estruturação social, reforça a necessidade de atenção ao potencial de agência. Compreender agência enquanto capacidade de fazer uma diferença (Giddens, 1978, 2003), enquadrando a relação entre poder e ação precedente a subjetividade, não implica rejeitar a possibilidade de regularidade na conduta ou a concepção de uniformidades trans-históricas (Cohen, 1999). Implica a rejeição de um determinismo radical e de um voluntarismo exagerado, de modo que a discussão a esse respeito contemple as circunstâncias históricas e contextuais, no sentido de reconhecer a assimetria no acesso a recursos, estabelecendo uma dialética de controle, bem como regras e recursos na definição do âmbito das práticas passíveis de serem exercidas por um agente (Cohen, 1999).

Segundo Friedland e Alford (1991), não se trata de uma questão de especificação do racional ou do irracional. Trata-se do exame de ordens transracionais variadas, nas quais a formação de preferências e de utilidade é histórica e institucionalmente estruturada e definida. De acordo com Beckert (1999), agência e padrões institucionais podem ser vistos como duas forças interdependentes que se desestabilizam, mas que atuam como mecanismos de coordenação de um sistema social. Ao mesmo tempo em que agentes estrategicamente pressionam estruturas institucionalizadas, normas sociais ou regras legalmente sustentadas, paradoxalmente, influenciam os modos de ação e as bases para avaliação de alternativas (Beckert, 1999; Scott, 2001).

Para fins de maior esclarecimento, vale resgatar a análise de Ackroyd (2000) sobre organizações, na qual ele afirma que elas também representam um tipo de instituição da sociedade contemporânea experimentado como real. Se esse raciocínio for coerente, elas ganham status ontológico e participam enquanto meio e resultado da estruturação social. Na medida em que são objetivadas, suas propriedades e relações passam a representar parâmetros para a ação, ao mesmo tempo em que, por assim serem consideradas e pela capacidade de mobilização que representam, tornam-se meios pelos quais estruturas sociais são modeladas ou reproduzidas. Assumindo ainda a discussão precedente sobre campo enquanto estrutura, toda a lógica de relacionamento social deve ser considerada, tanto na direção de estabelecimento de um sistema de posiçãoprática como de serem objeto de referência ou parâmetros para as ações organizacionais. Dessa forma, é viável considerar que relacionamentos organizacionais na estruturação do campo são construídos, num certo sentido em que são relevantes para os agentes, que escolhem a natureza das relações, e por conseguinte, das redes de relacionamento decorrentes. 
Além disso, sob uma ontologia de potenciais coerente com a abordagem estruturacionista, não se atribui prioridade trans-histórica ou universal às práticas ou processos específicos de reprodução social (Cohen, 1999). Ao mesmo tempo, admite-se a pressuposição de uma ontologia necessária, mas suficientemente flexível para aceitar um conhecimento transitivo-contingente dirigido ao objeto em questão e construído por meio de análise e pesquisa científica (Reed, 2005b). Assim compreendida, a perspectiva de análise de campos organizacionais requer cuidados que vão além das preferências teóricas, já que está no âmbito de pressupostos ontológicos e compromissos epistemológicos.

Dessa forma, admite-se certa possibilidade de relativização epistemológica, no sentido de aceitação de teorias substantivas que, enquanto corpo de conhecimento historicamente contextualizado, estão sujeitas a refutação empírica. Porém, de forma mais fundamental, que focalizem a elucidação de mecanismos ou estruturas gerativas (potenciais), constitutivas de processos e eventos sociais gerados ou transformados a partir de uma ampla gama de possibilidades empiricamente discerníveis (Cohen, 1999; Hedstrom \& Swedberg, 1996). Como bem observa Ekstrom (1992), nesse tipo de análise a preocupação central é a explicação e não a previsão:

causas não são nem eventos, nem objetos, mas propriedades ... efetivas/ produtivas e que se escondem por trás de uma seqüência de eventos e mudanças constantes que podem ser observadas no mundo real ... .Essas propriedades operativas que a análise causal tenta revelar existem pela necessidade relativamente independente de seus efeitos, mas as relações entre essas propriedades e os efeitos observáveis são contingentes tanto quanto sejam dependentes do contexto específico em que estudamos (p. 114).

\section{Conclusão}

A explicação é o aspecto fundamental da análise social. Tal afirmação implica reconhecer que a dupla hermenêutica inerente à atividade de pesquisa social, da forma como é referida por Giddens (1978, 2003), faz-se presente e envolve o fato de, enquanto cientistas sociais, utilizarmos conceitos para explicar outros conceitos, de modo que, por não estarmos em posição privilegiada em relação a outros atores, as implicações acerca do conhecimento da realidade se fazem vinculadas ao pressuposto de necessidade ontológica e limitação epistemológica (Acroyd \& Fleetwood, 2000; Zeuner, 2001). Essa limitação significa, nas palavras de Reed (2005b, p. 1665), que a ciência e o conhecimento produzido por ela não podem fornecer uma garantia absoluta e universal da complexidade dos processos 
e coisas reais, mas podem especificar um critério de validade para o argumento, a análise, a experimentação e a explicação, que, por sua vez, servem como base para a contraposição entre explicações rivais.

Dessa forma, a análise envolve a possibilidade de revisão conceitual, que, em contrapartida, implica também na forma de ver o mundo, reconsiderando as estruturas, mecanismos e relações que condicionam e, simultaneamente, são produto da agência humana, e que proporcionam uma influência causal no processo de estruturação de campos organizacionais.

Retornando às diferentes perspectivas teóricas sobre campo organizacional, tratadas neste trabalho, pode-se partir para duas posições em termos de sua avaliação: (a) análise de seu poder explicativo; ou (b) relativização epistemológica. A primeira posição inicia o debate, mas cria uma busca pela proeminência, numa lógica de exclusão. A segunda sugere que cada uma das perspectivas indica uma direção na relação social, o que poderia expressar a faceta parcial delas e, mais do que isso: o constructo campo organizacional constitui um corpo de conhecimento em permanente desenvolvimento, apresentando uma dimensão intransitiva ontologicamente; assim, as abordagens alternativas operam no nível do conhecimento científico (de interpretação dos mecanismos gerativos) e não se exluem necessariamente, mas definem seu caráter provisório e contingente. Nessa linha de raciocínio, qualquer enunciado sobre um sentido proeminente das relações que definem o grau de estruturação de um campo não deixa de ser arbitrário.

Portanto, em concordância com as idéias de Bhaskar (1998), afirmamos que a análise de campos organizacionais deve pressupor o surgimento de estruturas ou mecanismos pré-existentes, com propriedades gerativas que potencializam os eventos observáveis, que, por sua vez, podem ser experimentados empiricamente. Cada uma dessas dimensões analíticas está dialeticamente relacionada às demais e umas não podem ser reduzidas às outras. Ademais, dispostas dessa maneira, tais considerações só podem fazer sentido diante da natureza relacional dos sistemas sociais e de um pressuposto de ontologia potencial. Assim, a dualidade da estrutura, referente à mútua constituição entre estrutura e agência, bem como a dualidade da práxis, enquanto produção propositada e (re)produção não consciente das propriedades estruturais da sociedade ${ }^{(8)}$, são aspectos presentes no arcabouço analítico proposto.

Uma das conseqüências dessa abordagem é o fato de não fundir agência e estrutura, abrindo uma janela temporal para a análise - um dualismo analítico (Archer, 1982, 1998), conforme está ilustrado na Figura 2 - que possibilita e viabiliza a pesquisa, sem abandonar a recursividade estruturacionista. A 
estratificação de níveis de realidade (estruturas, eventos observáveis e experiência empírica), explicitado anteriormente, envolve um componente temporal na análise de campo. Desse modo, o esforço de explicação da estruturação do campo organizacional passa a admitir um ponto de partida analítico composto por condições estruturais (Archer, 1982, 1998), ou padrões e mecanismos préexistentes, incluindo regras, recursos e estruturas de relacionamentos ou sistemas de posição-prática, que exercem implicações causais sobre um momento posterior de interação social, em que a produção ou reestruturação social é promovida pelos agentes, dadas a natureza e as condições estruturais pré-existentes com as quais interagem.

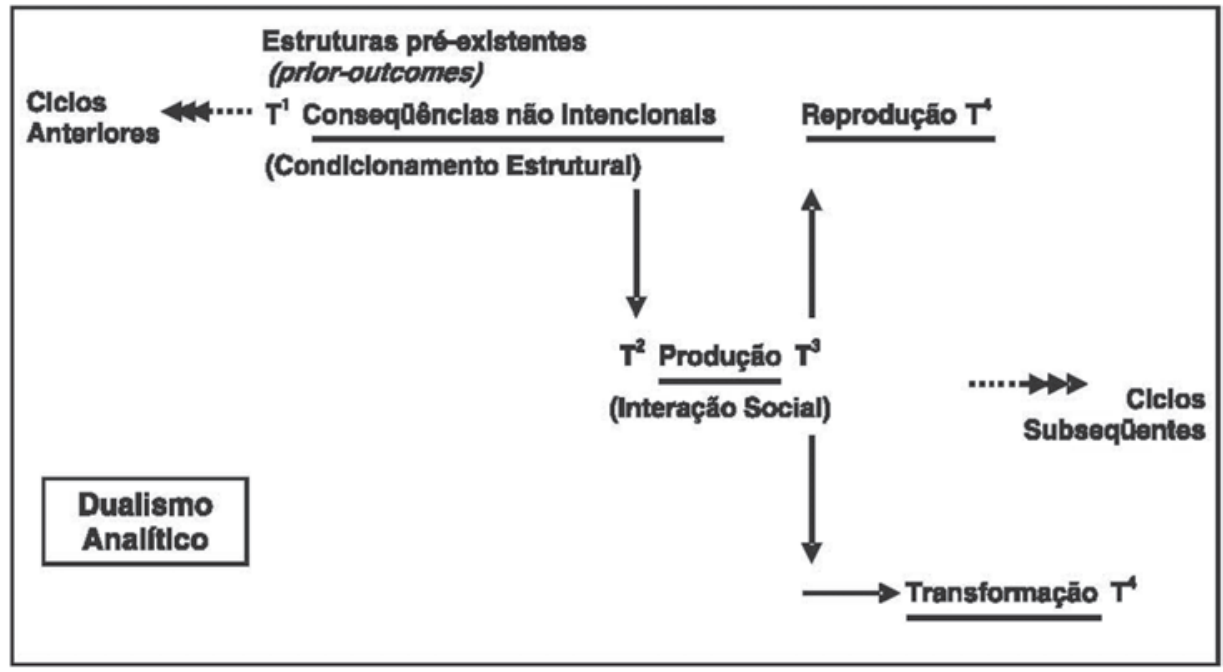

Figura 2. Dualismo Analítico

Fonte: Archer, M. S. (1998). Realism and morphogenesis (p. 376). In M. Archer, R. Bhaskar, A. Collier, T. Lawson, \& A. Norrie (Eds.), Critical realism: essential readings (pp. 356-381). London: Routledge.

Em tempo: a idéia de se propor como recurso metodológico o dualismo analítico não implica afirmar que há uma relação de causalidade empírica ou mecânica entre estrutura e agência, embora se reconheça o relacionamento e algum grau de condicionamento estrutural. Como já salientamos, isso não deve ser interpretado num sentido ahistórico, determinista ou de reificação estrutural. A significância causal e analítica das estruturas sociais nessa abordagem deve ser compreendida como operante a partir dos motivos e ações dos atores, intrinsecamente relacionada com sua capacidade de agência, influenciando, mas não determinando, sua atividade social em favor da reprodução ou transformação das relações, regras e recursos institucionalizados (ver dualidade da práxis e ontologia dos potenciais, que discutimos anteriormente). Campos e organizações podem, 
portanto, ser conceituados como instituições (Ackroyd, 2000) ou formas estruturais duradouras, que podem ser produzidas, reproduzidas e transformadas a partir das relações sociais em curso (Reed, 2000), embora, ao mesmo tempo, representem o processo de engajamento social a um sistema de posição-prática que possibilita sua própria transformação ou reprodução.

Tendo em vista que os integrantes de um campo estão relacionados aos demais e que todos eles exercem mútua influência num contexto social, que define as bases de significação (Scott, 1987), não seria demasiado afirmar que as redes de relacionamentos, tais como são vislumbradas por seus integrantes, jamais possam ser completamente apreendidas, uma vez que a perspectiva de análise e o menu de opções para ação são socialmente influenciados. Para DiMaggio e Powell (1983) trata-se do reconhecimento de condicionantes estruturais, que influenciam a amplitude de escolhas que os atores percebem como racionais ou prudentes. Na visão da teoria da estruturação de Giddens (2003): “o que o ‘indivíduo’ é não pode ser considerado óbvio. ... História não significa "práticas humanas sem mestre'. É a temporalidade de práticas humanas, modelando e sendo modelada por propriedades estruturais" (p. 258-259).

Em decorrência desse raciocínio, um dos aspectos mais contraditórios acerca do estudo de campos organizacionais passa a ter condições de ser equalizado. Trata-se do problema da definição de fronteiras. Bourdieu (2003) afirma que, pelo fato de sempre ser conhecido a posteriori, um campo é sempre considerado caso particular do possível. Na linha de argumentação que adotamos neste trabalho, essa afirmação de Bourdieu converge com a noção de que o conhecimento científico é, também, sempre produzido a posteriori e sem condições de ser equacionado com a experiência direta (Bhaskar \& Lawson, 1998). Pressupõe a existência de estruturas e mecanismos gerativos subjacentes ao campo em seu nível ontológico mais profundo; porém, ao se considerar o aspecto analítico, é uma questão lógica aceitar a impossibilidade de se alcançar essa realidade social em toda a sua complexidade. Assim, qualquer análise é sempre uma projeção; ou seja, é epistemologicamente relativa por sua dependência de conceitos construídos e da própria especificidade espaciotemporal. Portanto, a definição de fronteiras é sempre tratada analiticamente, em razão do delineamento de pesquisa selecionado, estando, então, comprometida com o pressuposto ontológico e sendo epistemologicamente limitada na própria medida que mecanismos ou estruturas que explicam certas regularidades possam ser revelados.

No que se refere ao debate sobre estruturação na perspectiva de Giddens ou de Bourdieu, a argumentação que desenvolvemos neste trabalho considera estrutura não apenas como regras e recursos, mas também como relações 
posições-prática. Tal entendimento pode conduzir ao engano de se concluir que estamos colocando em nova roupagem a perspectiva de campos sociais de Bourdieu por ele também enfatizar que a aparência opera sobre posições relativas de espaços de relações, ainda que invisíveis, e que se constituem na realidade primeira e última (Misoczky, 2003). No entanto, cabe uma ressalva: o mecanismo gerativo subjacente, que orienta essas diferenças de posição aparente, está associado à estrutura de distribuição de formas de poder, localizados no tempo e espaço. $\mathrm{O}$ enfoque que adotamos pretende suplantar essa perspectiva em dois movimentos: (i) revisando a abordagem de poder; e (ii) ampliando, em paralelo, as possibilidades de estruturas ou mecanismos gerativos subjacentes - regras, recursos e relações. Entendemos que a capacidade explicativa é maior sob uma ontologia potencial, sustentada em noção mais abrangente de poder, localizado na agência. Embora, sob esse prisma, não se rejeite as conseqüências apresentadas por Bourdieu em sua explicação sobre a estruturação social, elas são colocadas tão somente como possibilidade na complexidade do mundo social.

À guisa de finalização, procuramos com as formulações apresentadas ao longo deste artigo reposicionar o debate sobre campos organizacionais. De acordo com os argumentos traçados, as implicações vão além de preferências teóricas. A escolha de uma ou outra perspectiva sobre campos organizacionais pode favorecer linhas de análise institucional que dêem preferência a determinados tipos de interpretação. Dessa forma, no que se refere ao propósito deste artigo, refletir sobre diferentes possibilidades analíticas e metodológicas deve constituir preocupação que atinge o cerne da abordagem institucional nos estudos organizacionais. $\mathrm{O}$ aspecto fundamental a ser considerado trata da plausibilidade de se utilizar diferentes conceitos, dependendo dos objetivos de pesquisa, com o risco de vieses nas interpretações ou incoerência entre pressupostos ontológicos e epistemológicos e a abordagem institucional adotada.

As considerações precedentes sobre campo organizacional sugerem certos princípios analíticos, especialmente aqueles associados à recursividade e à historicidade. No processo de estruturação de um campo organizacional estrutura e agência se pressupõem mutuamente. Assim, a ação intencional, seja por disputa de poder ou de alcance de objetivos, está enquadrada em uma dinâmica que não separa diferentes dimensões da interação social. Os relacionamentos dispostos num campo, mesmo que se submetam em primeira instância àqueles aspectos associados, por exemplo, a recursos ou dominação, não estão desvinculados de outras ordens sociais ligadas à sua legitimação e significação. Além disso, enquanto arena institucional recursivamente definida, um campo representa parâmetros para a ação, ou um sistema de referências em constante elaboração, significativo para os atores sociais. Portanto, todo o conjunto de possíveis relacionamentos, passíveis de serem representados por meio de redes sociais, precisa também ser 
reconhecido enquanto significado, o que torna de difícil aceitação, pelo menos conceitualmente, as perspectivas discutidas anteriormente, já que todas elas atribuem, isoladamente e a priori, o sentido envolvido nas relações sociais. Campos são fenômenos históricos e sua localização espaciotemporal é relevante para a compreensão longitudinal de processos de institucionalização, reconhecendo que neles estão associadas a criação de ordens simbólicas e modelos de relacionamento social, de modo que, sem a compreensão dessa especificidade institucional e histórica, qualquer proposta de análise é limitada.

\section{Artigo recebido em 21.02.2006. Aprovado em 30.05.2006.}

\section{NOTAS}

${ }^{1}$ Versão preliminar deste artigo foi apresentada e publicada nos anais do EnEO 2006 - $4^{\circ}$ Encontro de Estudos Organizacionais da ANPAD -Associação Nacional de Pós-Graduação e Pesquisa em Administração, realizado no Brasil, em junho de 2006.

${ }^{2}$ Os autores agradecem aos Professores Charles Kirschbaum, João Marcelo Crubellate e Valéria Silva da Fonseca os valiosos comentários feitos com base em versão preliminar do artigo. A consideração desses comentários resultou em aperfeiçoamentos relevantes, mas ressaltamos que a responsabilidade pela versão final é exclusivamente dos autores do artigo.

${ }^{3}$ Os artigos sobre campo organizacional foram selecionados dos anais do EnANPAD (1998 a 2005) e do EnEO (2000 a 2004), além de todos os números dos seguintes periódicos: RAC, RAE, RAE Eletrônica, RAUSP, REAd, Cadernos Ebape, Cadernos de Pesquisa em Administração da USP. Da RAP foi considerado apenas o período 2000 a 2005, e da O\&S foram considerados somente os números disponíveis on-line. Foram identificados 25 artigos, escritos por 23 autores distintos. No que diz respeito às referências, verificou-se a citação a 17 autores internacionais, com um total de 149 referências nos 25 artigos. Para a elaboração da rede ilustrada na Figura 1 foi utilizado o software UCINET 6 (Borgatti, S. P., Everett, M. G., \& Freeman, L. C. (2002). UCINET for Windows: Software for social network analysis. Boston: Harvard Analytic Technologies) no formato 2-mode para redes de filiação entre artigos e referências específicas ao conceito de campo.

${ }^{4}$ A análise de Ackroyd (2000) acerca do caráter especial do nível organizacional na estruturação social é considerada adequada para os fins deste artigo; no entanto, não compartilhamos sem ressalvas de seu posicionamento crítico sobre organizações.

${ }^{5}$ A abordagem defendida nesse artigo reconhece que o isomorfismo possa ser um indicador do grau de estruturação de um campo organizacional, mas não o considera com exclusividade. A complexidade e a multiplicidade de interação no campo proporcionam diferentes contextos de referência que se influenciam mutuamente. Assim, mais do que promover o isomorfismo, as relações dentro de um campo podem e são em grande medida contraditórias, embora enquadradas em lógicas de ação que possibilitam alguma regularidade e continuidade.

${ }^{6}$ Giddens $(1978,2003)$ define estrutura como regras e recursos gerativos presentes na interação social ao longo de sua (re)produção recursiva nas práticas sociais. Assim, relações, inerentes a esse processo de estruturação, bem como as posições sociais ocupadas, seriam decorrentes de 
propriedades ou princípios estruturais de sistemas sociais. Nesse artigo, em concordância com as críticas de Cohen (1999), Mingers (2003) e com preceitos do realismo crítico, admite-se que os próprios relacionamentos pré-existentes e estruturalmente representados nas relações sociais atuam sobre o processo de (re)produção social (de regras e recursos potencializados na agência).

${ }^{7}$ Nesse ponto, resgata-se uma crítica a teoria da estruturação referente a sua incapacidade de justificar comportamentos divergentes no sistema social. Na abordagem defendida no artigo, isso decorre da influência causal do sistema de relacionamentos estabelecido que acomoda potenciais de transformação, como interesses, nas posições em relações sociais (ver Porpora, 1998).

${ }^{8}$ De acordo com Bhaskar, R. (1983). Beef, structure and place: notes from a critical naturalist perspective (p. 84). Journal for the Theory of Social Behavior, 13(1), 81-96, "It is because the social structure is always a given, from the perspective of intentional human agency, that I prefer to talk about reproduction and transformation than of structuration as Giddens does (although I believe our concepts are very close). For me structuration still retains voluntaristic connotations - social practice is always, so to speak, restructuration".

\section{Referências Bibliográficas}

Ackroyd, S. (2000).

Connecting organization and societies: a realist analysis of structures. In S. Acroyd \& S. Fleetwood (Eds.), Realist perspectives on management and organizations (pp. 87-108). London: Routledge.

Ackroyd, S., \&

Fleetwood, S. (2000).

Realism in contemporary organization and management studies. In S. Acroyd \& S. Fleetwood (Eds.), Realist perspectives on management and organizations (pp. 3-25). London: Routledge.

Archer, M. S. (1982).

Morphogenesis versus structuration: on combining structure and action. The British Journal of Sociology, 33(4), 455-483.
Archer, M. S. (1998).

Realism and morphogenesis. In M. Archer, R. Bhaskar, A. Collier, T. Lawson, \& A. Norrie (Eds.), Critical realism: essential readings (pp. 356381). London: Routledge.

Beckert, J. (1999).

Agency, entrepreneurs, and institutional change: the role of strategic choice and institutionalized practices in organizations. Organization Studies, 20(5), 777-799.

Bertilsson, M. (1984).

The structuration theory: prospects and problems. Acta Sociologica, 27(4), 339-353.

Bhaskar, R. (1998).

General introduction. In M. Archer, R. Bhaskar, A. Collier, T. Lawson, \& A. Norrie (Eds.), Critical realism: essential readings (pp. ix-xxiv). London: Routledge. 
Bhaskar, R., \&

Lawson, T. (1998).

Introduction: basic texts and developments. In M. Archer, R. Bhaskar, A. Collier, T. Lawson, \& A. Norrie (Eds.), Critical realism: essential readings (pp. 3-15). London: Routledge.

Bourdieu, P. (1983).

O campo científico. In R. Ortiz (Ed.), Pierre Bourdieu: sociologia (pp. 122-155). São Paulo: Ática.

Bourdieu, P. (1985).

The social space and the genesis of groups. Social Science Information, 24(2), 195-220.

Bourdieu, P. (1989).

Social space and symbolic power. Sociological Theory, 7(1), 14-25.

Bourdieu, P. (1990).

Coisas ditas. São Paulo: Brasiliense.

Bourdieu, P. (1992).

A economia das trocas simbólicas (3a ed.). São Paulo: Perspectiva.

Bourdieu, P. (1996).

Razões práticas: sobre a teoria da ação. Campinas: Papirus.

Bourdieu, P. (2003).

O poder simbólico (3a ed.). Rio de Janeiro: Bertrand Brasil.

Bourdieu, P. (2004).

Os usos sociais da ciência: por uma sociologia clínica do campo científico. São Paulo: UNESP.

Bourdieu, P., \&

Wacquant, L. J. D. (1992).

An invitation to reflexive sociology.

Chicago: University of Chicago Press.
Brint, S., \&

Karabel, J. (1991).

Institutional origins and transformations: the case of American community colleges. In W. W. Powell \& P. J. DiMaggio (Eds.), The new institutionalism in organizational analysis (pp. 337-360). London: University of Chicago Press.

Bryant, C. G. A., \&

Jary, D. (2001).

Anthony Giddens: a global social theorist. In C. G. A. Bryant \& D. Jary (Eds.), The contemporary Giddens (pp. 3-39). New York: Palgrave Macmillan.

Chia, R. (2003).

Ontology: organization as "world-making". In R. Westwood \& S. Clegg (Eds.), Debating organization: point-counterpoint in organization studies (pp. 98-113). Malden: Blackwell.

Cohen, I. (1999).

Teoria da estruturação e práxis social. In A. Giddens \& J. Turner (Eds.), Teoria social hoje (pp. 393-446). São Paulo: UNESP.

Coser, C., \&

Machado-da-Silva, C. L. (2004, setembro). Isomorfismo na rede de relacionamentos do espaço social de Videira-SC. Anais do Encontro Nacional dos Programas de PósGraduação em Administração, Curitiba, PR, Brasil, 28.

Davis, G. F., \&

Marquis, C. (2005).

Prospects for organization theory in the early twenty-first century: institutional fields and mechanisms. Organization Science, 16(4), 332343. 
DiMaggio, P. J. (1986).

Structural analysis of organizational fields: a blockmodel approach. In B. M. Staw \& L. L. Cummings (Eds.), Research in Organizational Behavior (Vol. 8, pp. 335-370). Greenwich: JAI Press.

DiMaggio, P. J. (1991).

Constructing an organizational field as a professional project: US art museums, 1920-1940. In W. W. Powell \& P. J. DiMaggio (Eds.), The new institutionalism in organizational analysis (pp. 267-292). London: University of Chicago Press.

DiMaggio, P. J., \&

Powell, W. W. (1982).

The iron cage revisited: conformity and diversity in organizational fields [Working Paper]. Institution for Social and Policy Studies, Yale University, 52.

DiMaggio, P. J., \&

Powell, W. W. (1983).

The iron cage revisited: Institutional isomorphism and collective rationality in organizational fields. American Sociological Review, 48(2), 147-60.

DiMaggio, P. J., \&

Powell, W. W. (1991).

Introduction. In W. W. Powell \& P. J. DiMaggio (Eds.), The new institutionalism in organizational analysis (pp. 1-38). London: University of Chicago Press.

Ekstrom, M. (1992).

Causal explanation of social: the contribution of Max Weber and of critical realism to a generative view of causal explanation in social science. Acta Sociologica, 35(2), 107122.

Emirbayer, M., \&

Goodwin, J. (1994).

Network analysis, culture and the problem of agency. American Journal of Sociology, 99(6), 1411-1454.

Everett, J. (2002).

Organizational research and the praxiology of Pierre Bourdieu. Organizational Research Methods, 5(1), 56-80.

Fligstein, N. (1991).

The structural transformation of American industry. In W. W. Powell \& P. J. DiMaggio (Eds.), The new institutionalism in organizational analysis (pp. 311-336). London: University of Chicago Press.

Fligstein, N. (1999).

Fields, power, and social skill: a critical analysis of the new institutionalisms. Center for Culture, Organizations and Politics [Paper wps-1999-01]. Recuperado em 8 julho, 2004, de http://repositories.cdlib.org/ iir/ccop/ wps-1999

Fligstein, N. (2001).

Social skill and the theory of fields. Sociological Theory, 19(2), 105-125.

Friedland, R., \&

Alford, R. R. (1991).

Bringing society back in: symbols, practices, and institutional contradictions. In W. W. Powell \& P. J. DiMaggio (Eds.), The new institutionalism in organizational analysis (pp. 232-263). London: University of Chicago Press. 
Frumkin, P., \&

Kaplan, G. (2000).

Institutional theory and the micromacro link. Unpublished research paper. Recuperado em 16 novembro, 2001, de http://carbon.cudenver.edu/ \%20 gkaplan/Adobe\%20Documents/ $\% 20 \mathrm{Job} \% 20$ Paper\%202\%20$\begin{array}{lllllllll}\% & 2 & 0 & \mathrm{M} & \mathrm{i} & \mathrm{c} & \mathrm{r} & \mathrm{O} & -\end{array}$ Macro\%20Link\%20Paper.pdf

Giddens, A. (1978). Novas regras do método sociológico. Rio de Janeiro: Zahar.

Giddens, A. (1999).

Estruturalismo, pós-estruturalismo e a produção da cultura. In A. Giddens \& J. Turner (Eds.), Teoria social hoje (pp. 281-320). São Paulo: UNESP.

Giddens, A. (2001).

Em defesa da sociologia. São Paulo: UNESP.

Giddens, A. (2003).

A constituição da sociedade (2. ed.). São Paulo: Martins Fontes.

Hedstrom, P., \&

Swedberg, R. (1996).

Social mechanisms. Acta Sociologica, 39(3), 281-308.

Hensmans, M. (2003).

Social movement organizations: a metaphor for strategic actors in institutional fields. Organization Studies, 24(3), 355-381.

Hoffman, A. J. (1999).

Institutional evolution and change: Environmentalism and the U.S. chemical industry. Academy of Management Review, 42(4), 351-371.
Hoffman, A. J. (2001).

Linking organizational and field-level analyses: the diffusion of corporate environmental practice. Organization \& Environment, 14(2), 133-158.

Jepperson, R. L. (1991).

Institutions, institutional effects, and institutionalism. In W. W. Powell \& P. J. DiMaggio (Eds.), The new institutionalism in organizational analysis (pp. 143-163). London: University of Chicago Press.

Lahire, B. (2002).

Reprodução ou prolongamentos críticos? Educação \& Sociedade, 23(78), 37-55.

\section{Lau, R. W. K. (2004),}

Habitus and the practical logic of practice: an interpretation. Sociology, 38(2), 369-387.

Lawrence, T. B., \&

Suddaby, R. (2005).

Institutions and institutional work. Unpublished manuscript. Recuperado em 26 fevereiro, 2006, de http:// www.bus.ualberta.ca/ rsuddaby/ Publications/ Lawrence\%20and\% 20Suddaby \%20-\%20Institutions\% 20 and $\% 20$ Institutional $\% 20$ Work.doc

Leão, F. P. S., Jr. (2001, setembro).

Formação e estruturação de campos organizacionais: um modelo para análise do campo cultural. Anais do Encontro Nacional dos Programas de Pós-Graduação em Administração, Campinas, SP, Brasil, 25.

\section{Lizardo, O. (2004).}

The cognitive origins of Bourdieu's habitus. Journal for the Theory for Social Behavior, 34(4), 375-401. 
Machado-da-Silva, C. L., \&

Coser, C. (2004a, junho).

Argumentos estruturais para explicação do isomorfismo mimético em um campo organizacional. Anais do Encontro de Estudos Organizacionais, Atibaia, SP, Brasil, 3 .

Machado-da-Silva, C. L., \&

Coser, C. (2004b, setembro).

Organização focal e relações de poder em um campo organizacional. Anais do Encontro Nacional dos Programas de Pós-Graduação em Administração, Curitiba, PR, Brasil, 28.

Machado-da-Silva, C. L.,

Fonseca, V. S., \&

Crubellate, J. M. (2005).

Estrutura, agência e interpretação: elementos para uma abordagem recursiva do processo de institucionalização. Revista de Administração Contemporânea, $9\left(1^{\mathrm{a}}\right.$ Edição Especial), 9-39.

Mazza, C., \&

Pederson, J. S. (2004).

From press to e-media? The transformation of an organizational field. Organization Studies, 25(6), 875-896.

Mingers, J. (2003).

Can social systems be autopoietic? Bhaskar and Giddens' social theories [Working Paper], Canterbury Business School, University of Kent, Canterbury, Kent, United Kingdom.

Misoczky, M. C. (2003, setembro).

Pelo primado das relações nos estudos organizacionais: algumas indicações a partir de leituras enamoradas de Marx, Bourdieu e Deleuze. Anais do Encontro
Nacional dos Programas de PósGraduação em Administração, Atibaia, SP, Brasil, 27.

Mohr, J. W. (2000).

Bourdieu's relational method in theory and practice. Unpublished Manuscript, Presented at the $95^{\text {th }}$ American Sociological Association Meeting, Washington: USA. Recuperado em 14 fevereiro, 2006, de http://www.soc.ucsb.edu/ct/pages/ JWM/Papers/Bourdieu.pdf

Munir, K. A. (2005).

The social construction of events: a study of institutional change in the photographic field. Organization Studies, 26(1), 93-112.

Porpora, D. V. (1998).

Four concepts of social structure. In M. Archer, R. Bhaskar, A. Collier, T. Lawson, \& A. Norrie (Eds.), Critical realism: essential readings (pp. 339355). London: Routledge.

Powell, W. W.,

White, D. R.,

Koput, K. W., \&

Owen-Smith, J. (2005).

Network dynamics and field evolution: the growth of interorganizational collaboration in the life sciences. American Journal of Sociology, 110(4), 1132-1205.

Reed, M. (2000).

In praise of duality and dualism: Rethinking agency and structure in organizational analysis. In S. Acroyd \& S. Fleetwood (Eds.), Realist perspectives on management and organisations (pp. 45-65). London: Routledge. 
Reed, M. (2005b).

Doing the loco-motion: response to contu and willmott's commentary on 'The realist turn in organization and management studies'. Journal of Management Studies, 42(8), 16631673.

Reed, M. (2005a).

Reflections on the 'realism turn' in organization and management studies. Journal of Management Studies, 42(8), 1621-1644.

Schimidt, M. (1997).

Habitus revisited. American Behavioral Scientist, 40(4), 444-453.

Scott, W. R. (1987).

The adolescence of institutional theory. Administrative Science Quarterly, 32(4), 493-511.

Scott, W. R. (1991).

Unpacking institutional arguments. In W. W. Powell \& P. J. DiMaggio (Eds.), The new institutionalism in organizational analysis (pp. 164182). London: University of Chicago Press.

Scott, W. R. (1994).

Conceptualizing organizational fields: Linking organizations and societal systems. In H. Derlien, U. Gerhardt, \& F. Scharpf (Eds.), Systems rationality and parcial interests (pp. 203-221). Baden: Nomos.

Scott, W. R. (2001).

Institutions and organizations (2a ed.). Thousand Oaks: Sage.
Scott, W. R. (2004).

Reflections on a half-century of organizational sociology. Annual Review of Sociology, 30, 1-21.

Scott, W. R.,

Mendel, P., \&

Pollack, S. (2000).

Environments and fields: studying the evolution of a field of medical care organizations. II KNEXUS Research Symposium: on institutionalization of knowledge. Stanford: Stanford University. Recuperado em 23 agosto, 2002, de http://www.iis.stanford.edu/ docs/ knexus/RichardScott.pdf

Scott, W. R., \&

Meyer, J. W. (1983).

The organization of societal sectors. In J. W. Meyer \& W. R. Scott (Eds.), Organizational environments: ritual and rationality (pp. 129-153). Beverly Hills: Sage.

Scott, W. R., \&

Meyer, J. W. (1991).

The organization of societal sectors: propositions and early evidence. In W. W. Powell \& P. J. DiMaggio (Eds.), The new institutionalism in organizational analysis (pp. 108-140). London: University of Chicago Press.

Seo, M., \&

Creed, W. E. D. (2002).

Institutional contradictions, praxis, and institutional change: a dialectical perspective. Academy of Management Review, 27(2), 222-247.

Swedberg, R. (2004a).

Sociologia econômica: hoje e amanhã. Tempo Social, 16(2), 7-34. 
Swedberg, R. (2004b).

The toolkit of economic sociology [Working Paper Series]. Center for the Study of Economy and Society, Cornell University, Ithaca, NY, USA.

Thiry-Cherques, H. R. (2006).

Pierre Bourdieu: a teoria na prática. Revista de Administração Pública, 40(1), 27-55.

Vieira, M. M. F., \&

Carvalho, C. A. (2003, setembro).

Campos organizacionais: de wallpaper à construção histórica do contexto de organizações culturais em Porto Alegre e em Recife. Anais do Encontro Nacional dos Programas de Pós-Graduação em Administração, Atibaia, SP, Brasil, 27.

Warde, A. (2004).

Practice and field: revising Bourdieusian concepts [Working Paper]. Centre for Research on Innovation \& Competition, University of Manchester, Manchester, UK.

Warren, R. L. (1967).

The interorganizational field as a focus for investigation. Administrative Science Quarterly, 12(2), 396-419.

Washington, M. (2004).

Field approaches to institutional change: the evolution of the National Collegiate Athletic Association 19061995. Organization Studies, 25(3), 393-414.
White, D. R.,

Owen-Smith, J.,

Moody, J., \&

Powell, W. W. (2004).

Networks, fields and organizations: micro-dynamics, scale and cohesive embeddings. Computational \& Mathematical Organization Theory, 10(1), 95-117.

Whittington, R. (1992).

Putting Giddens into action: Social systems and managerial agency. Journal of Management Studies, 29(6), 693-712.

Zeuner, L. (2001).

Sociological concepts between construction and revision. Proceedings of the $5^{\text {th }}$ Annual IACR Conference. Roskilde, Denmark: International Association for Critical Realism. Recuperado em 3 novembro, 2005, de http://www.criticalrealism.demon.co.uk/ iacr/annual_conference.html

Zietsma, C., \&

Winn, M. I. (2005).

Reflections on process and process theorizing: revisiting our work "Organizational field power dynamics and the "War of the Woods"'. Unpublished Manuscript, Presented at the The First Organization Studies Summer Workshop on Theorizing Process in Organization Research, Santorini: Greece. 